\title{
Host-associated microbiomes are predicted by immune system complexity and climate
}

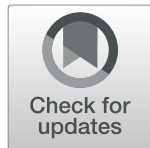

\author{
Douglas C. Woodhams ${ }^{1,2^{*}}$ (D), Molly C. Bletz ${ }^{1 \dagger}$, C. Guilherme Becker ${ }^{3}$, Hayden A. Bender ${ }^{1}$, Daniel Buitrago-Rosas ${ }^{1,2}$, \\ Hannah Diebboll', Roger Huynh', Patrick J. Kearns', Jordan Kueneman², Emmi Kurosawa', Brandon C. LaBumbard', \\ Casandra Lyons ${ }^{1}$, Kerry McNally ${ }^{4,5}$, Klaus Schliep ${ }^{1}$, Nachiket Shankar ${ }^{1}$, Amanda G. Tokash-Peters ${ }^{1,6}$, \\ Miguel Vences ${ }^{7}$ and Ross Whetstone ${ }^{1}$
}

\begin{abstract}
Background: Host-associated microbiomes, the microorganisms occurring inside and on host surfaces, influence evolutionary, immunological, and ecological processes. Interactions between host and microbiome affect metabolism and contribute to host adaptation to changing environments. Meta-analyses of hostassociated bacterial communities have the potential to elucidate global-scale patterns of microbial community structure and function. It is possible that host surface-associated (external) microbiomes respond more strongly to variations in environmental factors, whereas internal microbiomes are more tightly linked to host factors.

Results: Here, we use the dataset from the Earth Microbiome Project and accumulate data from 50 additional studies totaling 654 host species and over 15,000 samples to examine global-scale patterns of bacterial diversity and function. We analyze microbiomes from non-captive hosts sampled from natural habitats and find patterns with bioclimate and geophysical factors, as well as land use, host phylogeny, and trophic level/ diet. Specifically, external microbiomes are best explained by variations in mean daily temperature range and precipitation seasonality. In contrast, internal microbiomes are best explained by host factors such as phylogeny/immune complexity and trophic level/diet, plus climate.

Conclusions: Internal microbiomes are predominantly associated with top-down effects, while climatic factors are stronger determinants of microbiomes on host external surfaces. Host immunity may act on microbiome diversity through top-down regulation analogous to predators in non-microbial ecosystems. Noting gaps in geographic and host sampling, this combined dataset represents a global baseline available for interrogation by future microbial ecology studies.
\end{abstract}

Keywords: Biodiversity, Gut microbiome, Microbial ecology, Skin microbiome, Symbiosis, Wolbachia

\section{Background}

"A memory-based immune system may have evolved in vertebrates because of the need to recognize and manage complex communities of beneficial microbes."-McFallNgai 2007 [1].

\footnotetext{
* Correspondence: dwoodhams@gmail.com

${ }^{\dagger}$ Douglas C. Woodhams and Molly C. Bletz are co-first authors.

${ }^{1}$ Department of Biology, University of Massachusetts Boston, Boston, MA 02125, USA

${ }^{2}$ Smithsonian Tropical Research Institute, Roosevelt Ave. Tupper Building 401, 0843-03092 Panamá, Panama

Full list of author information is available at the end of the article
}

While global patterns of diversity and biogeography have been extensively studied in animals and plants, they are much less understood in microbes. In soil microbiomes, $\mathrm{pH}$ has been found to be a strong driver of ecosystem type [2], while in another study, environmental microbiomes were primarily driven by salinity [3]. The recent Earth Microbiome Project found that host microbiomes were distinct from environmental microbiomes, and for hosts, ecosystem type was an important driver. Microbiomes of plants and animals differed strongly, and host surfaces were different from digestiveassociated microbiomes [4]. A large study examining 
skin surface microbiomes across 205 amphibian species found strong correlations with bioclimatic factors [5], while digestive microbiomes of mammals were influenced by diet and gut morphology, and indeed distinct from environmental microbiomes [6]. A substantial role of biotic interactions in shaping microbial communities was also obvious from a strong bacterial-fungal antagonism revealed by global patterns in topsoil and ocean microbiomes [7], a pattern also revealed on hosts [8-11].

These studies are foundational for understanding large-scale microbial ecology patterns. Here, we use data of host-associated bacterial communities from the Earth Microbiome Project and 50 additional studies that meet our criteria for inclusion to produce a large dataset for analysis through a standardized pipeline (Fig. 1a). We examine 654 non-captive host species including plants, and invertebrate and vertebrate animals and perform separate analyses for digestive-associated (internal) and surface-associated (external) microbiomes from marine or terrestrial/aquatic habitats. With an increasing diversity of hosts examined for symbiosis with microbes, mechanisms driving these hostmicrobe interactions will become clear [12]. We hypothesized that external host-associated microbiomes would most strongly correlate with global bioclimate or other abiotic factors, while internal microbiomes would be more strongly associated with host factors such as phylogeny, and trophic level or diet.

Diverse microbial communities can assemble and coevolve with hosts and contribute important or even essential functions for host development, physiology, and health $[13,14]$. Detrimental alterations in the host's microbiome, or "dysbiosis", can lead to disease; thus, baseline descriptions of functional microbiomes are essential $[15,16]$. In the future, personalized medicine may utilize the microbiome for biomarkers for conditions of disease or health [17], and disease progression may be more readily predicted and described by changes in microbiota than by clinical symptoms or the presence of certain pathogenic agents [18, 19]. Functional characterization may be more meaningful than identity in microbial community profiles due to functional redundancy among microbes [20, 21]. However, characterizing core (prevalent among individuals) microbial communities may also be utilized to develop screening tools for host health or to understand ecoevolutionary dynamics [22, 23]. Here, we hypothesized that internal microbiomes may represent an extension of host phenotype; rather than functioning to reduce microbial diversity, complexity in host immune systems may be correlated with microbiome diversity across taxa. Furthermore, host microbiomes may be more strongly differentiated by predicted community function than by community composition given a multitude of species with overlapping functional capacities.

Meta-analysis of microbiomes through the growing body of next-generation sequencing data represents a new tool for ecologists and is a systematic approach to combining the results of multiple studies and synthesizing relevant data to gain new insights [4, 24]. This technique allows the synthesis of regional- and local-scale data to elucidate global-scale patterns of microbial community structure, function, and interaction, with indications for public health and extending to environmental policy [25]. Meta-analysis has been increasingly recognized as an important scientific approach, with many prominent researchers proposing standards for, and encouraging, its continued widespread use [25-27]. Human microbiomes have been the target of several metaanalyses, revealing insights that indicate microbial involvement in health as well as disease [28], and determining core microbiota associated with body sites [29]. Some meta-analyses have synthesized data in order to investigate disease, physiologic, and developmental states with large effect sizes [30,31]. Meta-analyses of nonhuman host taxa have found a potential link of convergent microbial symbioses between fish and mammals with salinity and trophic level being important drivers of fish gut microbiomes [32]. While diet also impacts mammal gut microbiomes [6], a study of 18 wild non-human primates indicated that the influence of host physiology and phylogeny was much stronger than diet [33]. Host selection also was found to be more important than diet or captivity status in avian guts [34]. Some key questions for microbiome meta-analyses are featured in Table 1, and while host-microbiome datasets are accumulating with time (Fig. 2), knowledge gaps are identified including gaps in regions sampled (Fig. 1b) and host groups with unstudied microbiomes (Fig. 3). Importantly, the eukaryotic and viral components of the microbiome remain a research frontier. The bacterial microbiome dataset and metadata accumulated here is a public resource and may provide future eco-evolutionary, veterinary, or medical insights. As an example, we investigate the bioclimatic correlates of the abundance of an arthropod symbiont that is increasingly important for disease vector control (Wolbachia $[59,60]$ ) across the global dataset we assembled.

\section{Results}

After combining microbiome datasets targeting the V4 region of $16 \mathrm{~S}$ rRNA gene obtained from Illumina platforms and using a standard analysis pipeline (Fig. 1a) [61] to identify sub-Operational Taxonomic Units (sOTUS), or unique sequence variants [27], we were able to compare data from 654 host species distributed globally. Samples ranged from 46 countries in 7 biomes and 


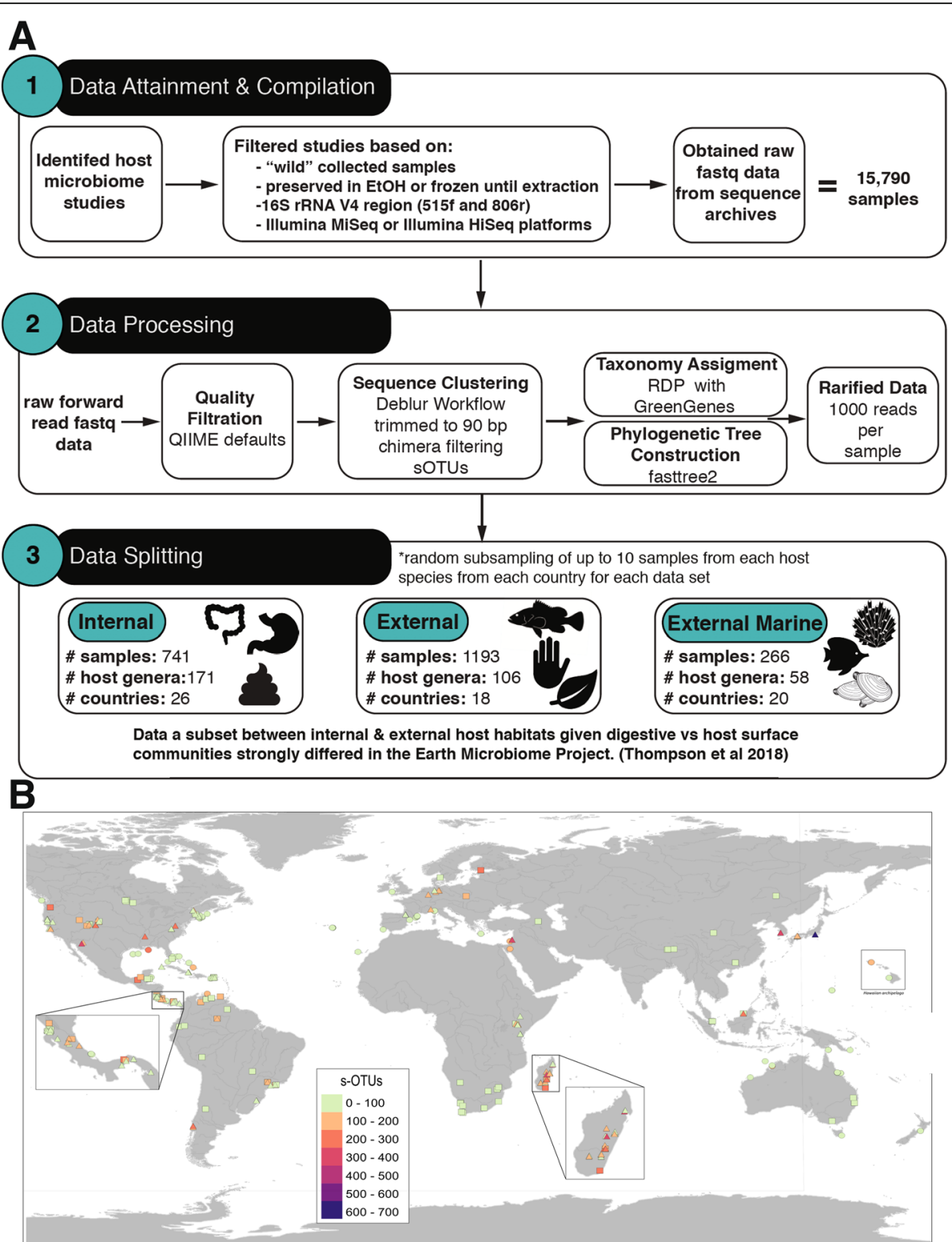

Fig. 1 Method schematic and geographic distribution of samples analyzed. a Method schematic for data attainment and compilation, data processing, and data splitting into three distinct subsets for subsequent analyses. $\mathbf{b}$ Map of the coverage of samples included in this study. Three types of host microbiome samples are represented: internal (squares), external (triangles), and marine external (circles). Sampling points are colorscaled by sub-Operational Taxonomic Unit (sOTU) richness. Areas with small territory size (such as Central America and Hawaiian Archipelago) and many sampling points with different types of samples (Madagascar) are shown zoomed-in in separate boxes. Map created with QGIS (Quantum GIS Development Team 2013) using a base global map from Natural Earth (naturalearthdata.com) with all geographic coordinates standardized to decimal degrees

from hosts including marine sponges $490 \mathrm{~m}$ below the sea surface to bar-headed geese at $3955 \mathrm{~m}$ elevation in the Himalayas. While representing a global sampling of hosts, visual inspection of the map of global distribution of samples suggests that hosts from much of Africa and Asia are underrepresented (Fig. 1b), and many eukaryotic clades have not been sampled, thus providing ample opportunities for future research (Fig. 3). We subset the 15,790 samples into 3 non-overlapping groups for separate analyses: internal $(N=741$ samples), external $(N=1193)$, and marine external microbiomes $(N=$ 266; Table 2, Fig. 1a). Given what has already been described by the Earth Microbiome Project, separate analyses are warranted based on host ecosystem type (marine as distinct from terrestrial/aquatic) and host internal or external body site [3].

For marine organisms, our analysis was limited to available external samples. For terrestrial/aquatic organisms, 
Table 1 Outstanding questions in host-microbiome research. Host-microbiome research is an emerging field. Knowledge gaps include the eukaryotic and viral components of the microbiome [35-37], novel bacterial clades and uncultured microbes [38-40], and large gaps in the geography and host taxa sampled for microbiome studies. Most studies to date have focused on human or other mammalian gut microbiomes, agricultural plants, and fish studies focused on aquaculture, leaving other vertebrate and invertebrate hosts underrepresented. Wild samples are needed to overcome alterations due to captivity [41, 42]. Recent efforts to place microbiomes within a macroecology context described patterns across scales [43], or metacommunity or community ecology contexts to learn about microbial migration $[44,45]$, community assembly and succession [46], and functions for host health [12, 47-49]

Frontiers in host-microbiome research

1) Are there dormant and active microbiome subsets of the host microbiome, and how do these subsets change with environmental conditions [50]? How does microbial antagonism and interaction protect hosts or facilitate host invasion [11]?

2) What are the effects of environmental change on colonization, dysbiosis, or adaptive microbiomes? Do abiotic conditions have stronger effects on ectotherms compared with endothermic hosts? Are microbial therapies effective [17, 51-53]?

3) What is the significance of core (stable through time and prevalent among individuals) vs peripheral (transitory or rare) microbiomes or gene functions including metabolic pathways in host populations, and is there a trade-off or shift in core microbiome with host immunity, anatomy, life stage, or environmental conditions? Are core microbiomes likely to be of use in personalized medicine or disease diagnostics? Are core microbiomes, particularly of non-human hosts, lost with industrialization $[31,54,55]$ ?

4) Metabolomics and functional analyses are a research frontier; do they require a renewed focus on culture-based research and genome sequencing [56-58]?

we divided analyses between internal and external samples. Internal microbiomes were primarily associated with the digestive system or whole organism samples in the case of insects. While the microbial communities in insects can differ with surface or organ sampled, for the sake of our analysis, we classified whole organism tissues as internal (Fig. 1a). This is consistent with descriptions of gut microbiomes driving the community structure of wholeorganism samples [62], and the lower quantity of bacterial cells on human skin vs. large intestine, for example [63]. External microbiomes were sampled from host surfaces including the skin, gill, or leaves, and analyzed separately.

We assembled an extensive collection of metadata for each sampled host, including host taxonomy, life stage, trophic level, and body site sampled, as well as environmental factors for each sampling location such as macroclimate metrics of temperature and precipitation, land cover, and elevation. We then visualized the dominant microbial taxa from each host class separately by host habitat and body region (internal, external; Fig. 4, Additional file 1: Figure S3), and performed analyses of alpha and beta diversity metrics. Results of all analyses can be reproduced with the data included in Additional files 2, 3, 4, 5, 6, 7, 8, 9, 10, 11, and 12 (see the "Methods" section and Additional file 1 for a description of the data files provided), or re-analyzed in the future as bioinformatics techniques continue to improve.

To analyze alpha diversity, including richness (number of sOTUs) and phylogenetic diversity of sOTUs, we carried out model selection (Additional file 1: Table S1), resulting in a reduced set of variables for inclusion in downstream path analyses: a temperature metric and a precipitation metric, normalized difference vegetation index (NDVI), and host phylogeny and trophic diet. Path analysis was used to test for the magnitude and significance of hypothesized causal connections and to determine direct vs. indirect influences on alpha diversity. Separate path models were run to examine how variables interacted to impact microbiome phylogenetic diversity or richness and were performed separately for internal and external microbiomes (Fig. 5). Latitude was excluded from path analyses because of multicollinearity with climatic variables (analyzed separately in Additional file 1: Figure S2).

Patterns of beta-diversity were analyzed by permutational analysis of variance (PERMANOVA) to determine variables of greatest importance in structuring the microbial communities (Additional file 1: Table S2). Internal microbiomes were most significantly structured by host class (explaining 14\% of the variation), as well as trophic diet, several bioclimatic factors, latitude, elevation, and NDVI (Additional file 1: Table S2). A principal coordinates analysis illustrates clustering of internal microbiome by host class and depicts the higher microbial diversity found in samples of mammals, amphibians, birds, and non-avian reptiles (crocodile and iguana) as compared to insects and carnivorous plants (Fig. 6a; Additional file 1: Tables S2, S3). External microbiomes were structured most strongly by bioclimatic factors (bioclim 2 and bioclim 15 explaining $60 \%$ and $7 \%$ of variation, respectively), as well as external habitat type (5\%) as compared to host class (not significant; Additional file 1: Table S2). Bioclim2 is a measure of mean diurnal temperature range and most significantly structured the external microbiome (Fig. 6b, Additional file 1: Figure S3). Because our dataset was heavily filtered to standardize sampling among host species and locales, we verified that we retained power to detect previously described patterns. For example, four human populations included in the dataset recapitulated previously described patterns including greater gut microbiome diversity in developing countries ([64]; Additional file 1: Figure S4). 


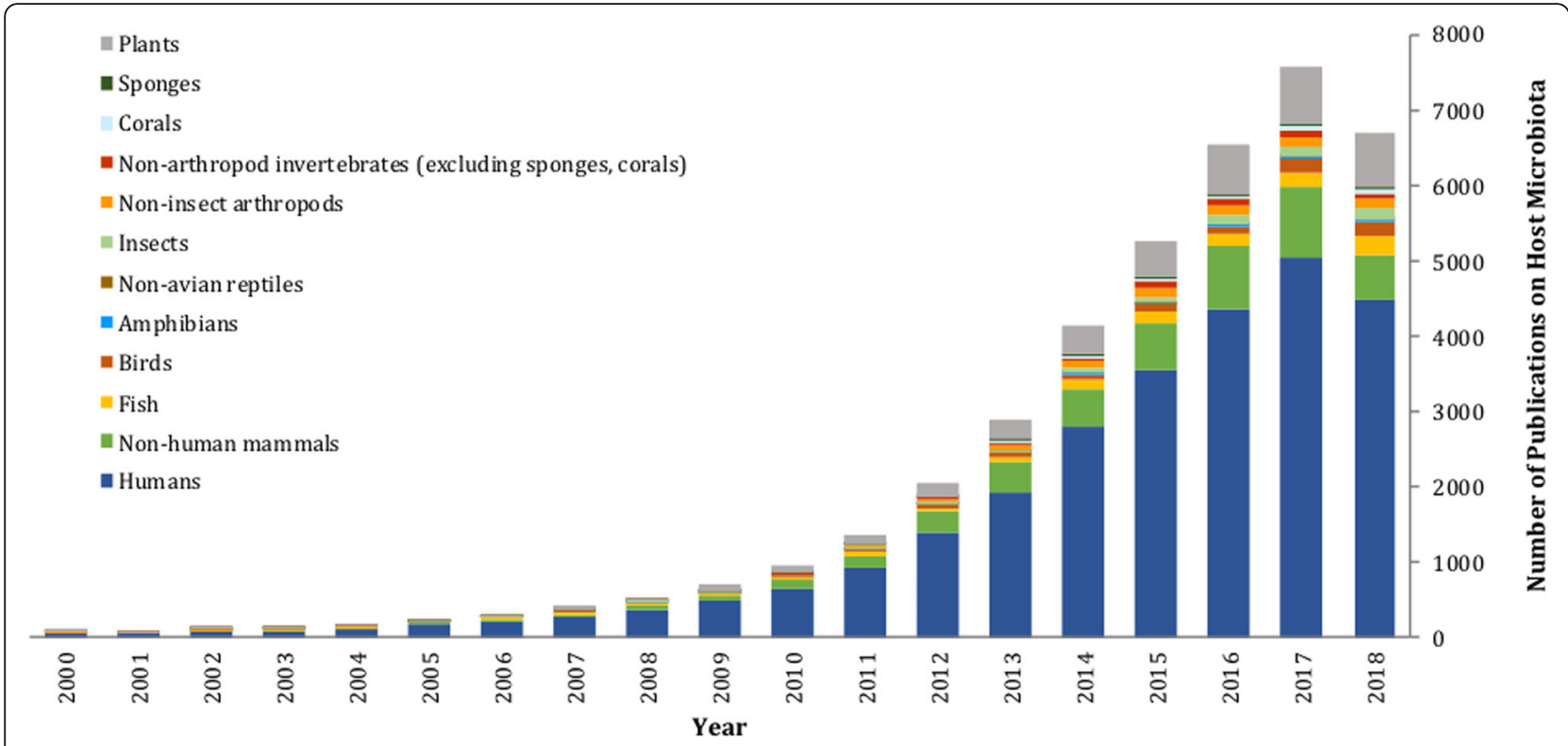

Fig. 2 Trends in published host-microbiome studies through time. Data based on a custom keyword statements within NCBI PubMed

Because host class had the strongest association with the internal microbiome structure, we examined this relationship in greater detail, hypothesizing that predicted function may provide further discrimination. We used PICRUSt (Phylogenetic Investigation of Communities by Reconstruction of Unobserved States) to examine functional properties of the internal microbiome [21]. We characterized the accuracy of this tool by comparing the weighted Nearest Sequenced Taxon Index (weighted NSTI) score across host classes and filtering samples above the cutoff score of 0.06 (Additional file 1: Figure S5). The major functional categories across host taxa included membrane transport, amino acid metabolism, and carbohydrate metabolism (Additional file 1: Figure S6). Functional capacities of the internal microbiomes were structured by similar variables as the microbial communities including host class (explaining 13\% of variation) as well as trophic diet, bioclimate variables, latitude, elevation, and NDVI (each explaining less than $5 \%$ of variation; Additional file 1: Table S2). Trophic diet was a significant factor of ecological interest, though explaining little variation. Some host taxa including Amphibia and Teleostei demonstrate developmental shifts in both trophic level and microbiome [46, 65-67]. A phylogenetic tree of internal microbiome phyla illustrated potential trends by host trophic level/diet in abundance of major groups such as decreasing Proteobacteria and increasing Firmicutes at higher trophic levels (Fig. 7). Profiles of carnivorous plants were distinct from animal carnivores. Shifts in major classes with four bacterial phyla are illustrated in Fig. $7 \mathrm{~b}$.
Eco-evolutionary patterns in immune complexity were examined to test a mechanistic hypothesis explaining trends in host microbiome diversity. Hosts with adaptive immune systems had significantly greater microbiome richness and phylogenetic diversity than hosts with only innate immunity (Wilcoxon, $P<0.001$; Fig. 8a). Complexity of host immune systems at a broad level was correlated with microbiome diversity (Fig. 8b). While strongly correlated with host phylogeny, the complexity of adaptive immune systems across hosts based on a review by Flajnik [68] was developed into a matrix and score for each host class (Additional file 1: Table S3). Inclusion of the scale of adaptive immune system complexity in the path model for internal microbiomes indicated a significant direct association with microbial phylogenetic diversity (Fig. 9).

The role and maintenance of core members of host microbiomes remains a research frontier, and we hypothesize a trade-off between immune complexity and abundance of core microbes defined specifically at the strain level (Table 1). A preliminary analysis based on a permissive definition of core bacteria $(80 \%$ prevalence among samples) is presented in Additional file 1: Table S3.

The dataset we assembled provides a broad overview of factors driving host microbiome structure, function, and diversity (Figs. 4, 5, and 6). It also provides a resource for comparative microbial ecology. As an example of its utility, we scrutinized the dataset for global trends in the distribution of Wolbachia, a genus of common Gram-negative bacteria known to be reproductive 


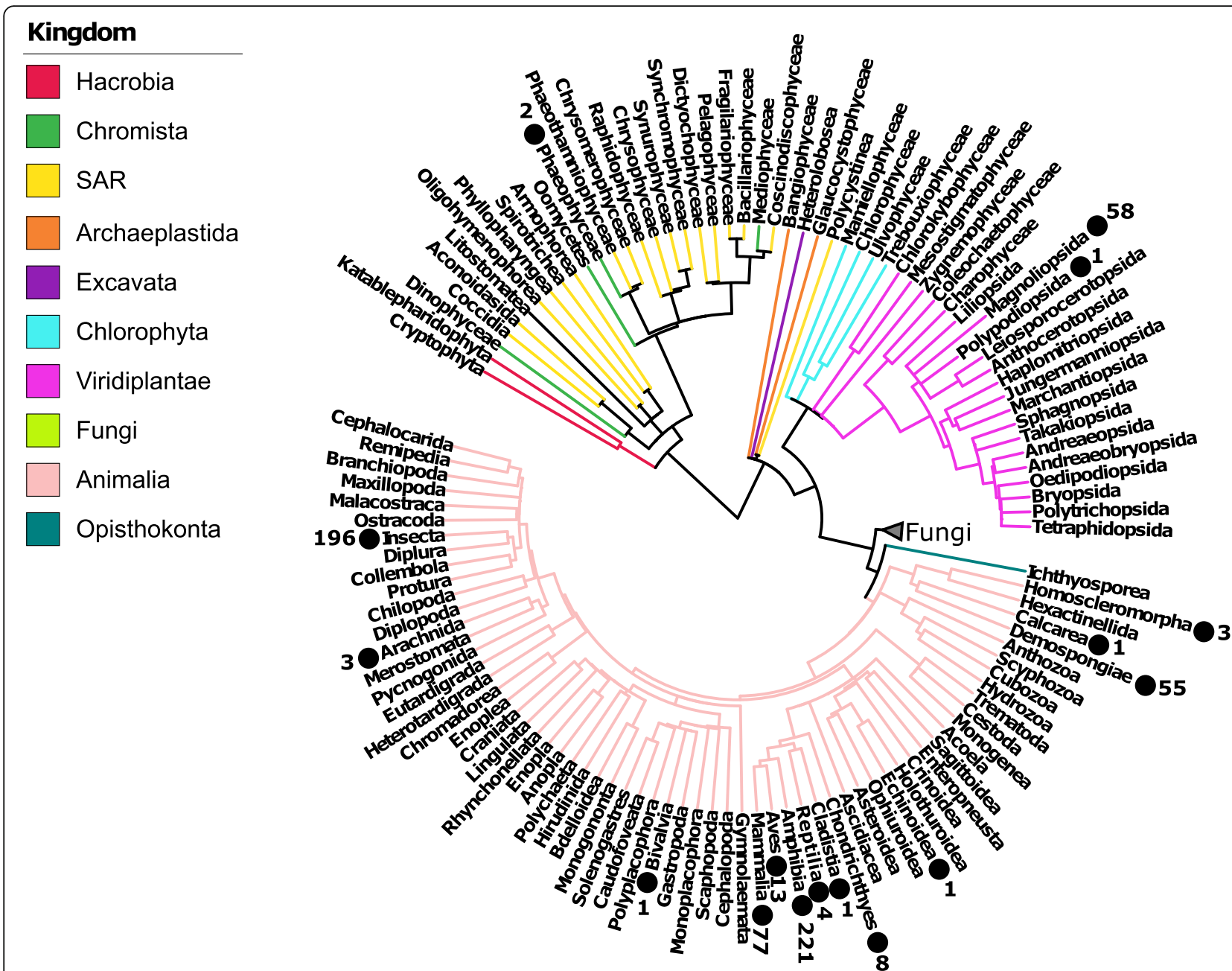

Fig. 3 Phylogenetic tree of selected eukaryotic hosts at the class level. Numbers adjacent to black circles indicate the number of species included in our dataset from that class. Groups' missing microbiome data are evident; however, only studies focusing on the V4 region of the rRNA gene were included. Tree was retrieved from TimeTree (http://www.timetree.org), which aggregates taxonomic and phylogenetic information from published literature. Interact with this tree at IToL: https://itol.embl.de/tree/1306494203341921544122745

parasites and serving as mosquito disease vector control agents; our data confirm these bacteria being mainly present in insects (Table 3) and find them most abundant in cool environments of the globe (Fig. 10). At a global scale, we thus describe novel patterns and lay the groundwork for future mechanistic studies on hostmicrobiome interactions.

\section{Discussion}

The assembly and composition of host-associated microbiomes are attendant with forces of ecology, evolution, host physiology, and immune function. Here, we examine microbiomes from 654 host species and begin where our current understanding trails off. That is, at the broadest scale, microbiomes can be differentiated first by free-living or host-association according to the Earth
Microbiome Project Ontology ([4]; Additional file 1: Figure S1), likely driven by both biotic and abiotic pressures. Salinity has a large effect on free-living microbiomes [4], and here, we analyze microbiomes on external host surfaces of marine organisms separately from those of terrestrial and aquatic hosts. Many other factors influence or interact with host microbiomes, and here, we examine whether these factors differ depending on whether the microbiome is from external host surfaces such as leaves, gill, or skin, or is internal to the host, including communities in the digestive and reproductive systems. Host immune complexity, though strongly correlated with host phylogeny, appears to influence both internal and external microbiomes in terms of diversity and community structure (Figs. 8 and 9). Indeed, internal microbiome phylogenetic diversity had a weak direct path from host phylogeny, but a strong 
Table 2 Summary statistics and metadata fields for the full dataset, partitioned for analyses by internal or external microbiomes of terrestrial and freshwater host organisms

\begin{tabular}{|c|c|c|c|c|c|}
\hline Metadata field & Description & Full dataset & Internal & External & $\begin{array}{l}\text { Marine_- } \\
\text { external }\end{array}$ \\
\hline Samples & sample runs included in this study & 15,790 & 741 & 1193 & 266 \\
\hline sOTU & exact sequence variants (sub-operational taxonomic units) & 175,709 & $17,544^{\mathrm{a}}$ & $28,410^{\mathrm{a}}$ & $5.077^{\mathrm{a}}$ \\
\hline Publications (by doi) & digital object identifier accession number of published studies & 51 & 23 & 13 & 6 \\
\hline Host Kingdom & https://www.itis.gov or http://www.eol.org & 2 & 2 & 2 & 2 \\
\hline Host Phyllum & https://www.itis.gov or http://www.eol.org & 8 & 3 & 2 & 4 \\
\hline Host Class & https://www.itis.gov or http://www.eol.org & 16 & 7 & 5 & 8 \\
\hline Host Order & https://www.itis.gov or http://www.eol.org & 80 & 26 & 23 & 27 \\
\hline Host Family & https://www.tiss.gov or http://www.eol.org & 177 & 65 & 52 & 45 \\
\hline Host Genus & https://www.itis.gov or http://www.eol.org & 427 & 171 & 106 & 58 \\
\hline Host species name & full scientific name of host organism & 654 & 204 & 239 & 78 \\
\hline Host taxid & $\begin{array}{l}\text { taxa id number for the host species from NCBI Taxonomy } \\
\text { Browser }\end{array}$ & 640 & 197 & 236 & 78 \\
\hline Collection timestamp & date of sampling in DD/MM/YYYY format & 1069 & 143 & 173 & 108 \\
\hline Countries & country from which samples were collected & 46 & 26 & 18 & 20 \\
\hline Latitude range (deg) & latitude in decimal degrees & $\begin{array}{l}-43.53 \text { to } \\
60.17\end{array}$ & -37.94 to 60.17 & $\begin{array}{l}-39.84 \text { to } \\
52.28\end{array}$ & $\begin{array}{l}-43.14 \text { to } \\
51.73\end{array}$ \\
\hline $\begin{array}{l}\text { Longitude range } \\
\text { (deg) }\end{array}$ & longitude in decimal degrees & $\begin{array}{l}-157.79 \text { to } \\
174.83\end{array}$ & -121.79 to 152.31 & $\begin{array}{l}-122.83 \text { to } \\
138.94\end{array}$ & $\begin{array}{l}-157.79 \text { to } \\
174.83\end{array}$ \\
\hline Elevation range $(\mathrm{m})$ & $\begin{array}{l}\text { GPS coordinates used to estimate elevation if not stated in } \\
\text { study }\end{array}$ & $\begin{array}{l}-490 \text { to } \\
3955\end{array}$ & -3 to 3955 & 17 to 3837 & -490 to 25 \\
\hline $\begin{array}{l}\text { microbial_habitat_ } \\
\text { type }\end{array}$ & internal, external, and whole organism & 3 & $\begin{array}{l}\text { internal and whole } \\
\text { organism }\end{array}$ & external & external \\
\hline internal_habitat_type & $\begin{array}{l}\text { digestive-associated, oral, nasal, lung, reproductive, leaf } \\
\text { internal, root internal, and n/a }\end{array}$ & 8 & 1 & $\mathrm{n} / \mathrm{a}$ & $\mathrm{n} / \mathrm{a}$ \\
\hline $\begin{array}{l}\text { digestive_habitat_ } \\
\text { type }\end{array}$ & foregut, fecal, cloacal, intestine, stomach, other and n/a & 7 & 5 & $\mathrm{n} / \mathrm{a}$ & $\mathrm{n} / \mathrm{a}$ \\
\hline external_habitat_type & leaf surface, root surface, animal surface, gill, and n/a & 5 & $\mathrm{n} / \mathrm{a}$ & 4 & 3 \\
\hline surrounding_habitat & freshwater, marine, terrestrial & 3 & $\begin{array}{l}\text { freshwater, } \\
\text { terrestrial }\end{array}$ & $\begin{array}{l}\text { freshwater, } \\
\text { terrestrial }\end{array}$ & marine \\
\hline lifestage & adult, juvenile/pupae, larvae, and infant & 4 & 4 & 3 & 2 \\
\hline sampling_month & month when the samples were collected & 12 & 12 & 12 & 12 \\
\hline trophic_diet & $\begin{array}{l}\text { scaled } 0=\text { primary producers, } 1=\text { herbivore, } 2=\text { omnivore, } 3= \\
\text { carnivore, } 4=\text { detritivore/scavenger }\end{array}$ & 5 & 5 & $\mathrm{n} / \mathrm{a}$ & $\mathrm{n} / \mathrm{a}$ \\
\hline preservation_method & sample storage by direct freeze, ethanol, RNA-later, or other & 4 & 4 & 3 & 2 \\
\hline extraction_method & name of DNA extraction kit & 15 & 5 & 6 & 2 \\
\hline biogeo_realm & https://en.wikipedia.org/wiki/Biogeographic_realm & 7 & 6 & 5 & 4 \\
\hline $\begin{array}{l}\text { Worldclim2 } \\
\text { bioclimatic variables }\end{array}$ & http://worldclim.org/version2; Fick et al 2017 & n/a & 8 & 8 & $\mathrm{n} / \mathrm{a}$ \\
\hline $\begin{array}{l}\text { Marine geophysical } \\
\text { variables }\end{array}$ & http://marspec.weebly.com/about.html; Sbrocco et al 2013 & $\mathrm{n} / \mathrm{a}$ & $\mathrm{n} / \mathrm{a}$ & $\mathrm{n} / \mathrm{a}$ & 11 \\
\hline $\begin{array}{l}\text { Immune Complexity } \\
\text { (binary) }\end{array}$ & inferred from host class information & $\mathrm{n} / \mathrm{a}$ & 2 & 2 & $\mathrm{n} / \mathrm{a}$ \\
\hline $\begin{array}{l}\text { Immune Complexity } \\
\text { (ordinal) }\end{array}$ & scale based on Flajnik et al 2018; & $\mathrm{n} / \mathrm{a}$ & $1-9$ & $1-9$ & $\mathrm{n} / \mathrm{a}$ \\
\hline
\end{tabular}

\footnotetext{
${ }^{a}$ sOTUs after rarefaction at 1000 reads per sample
} 


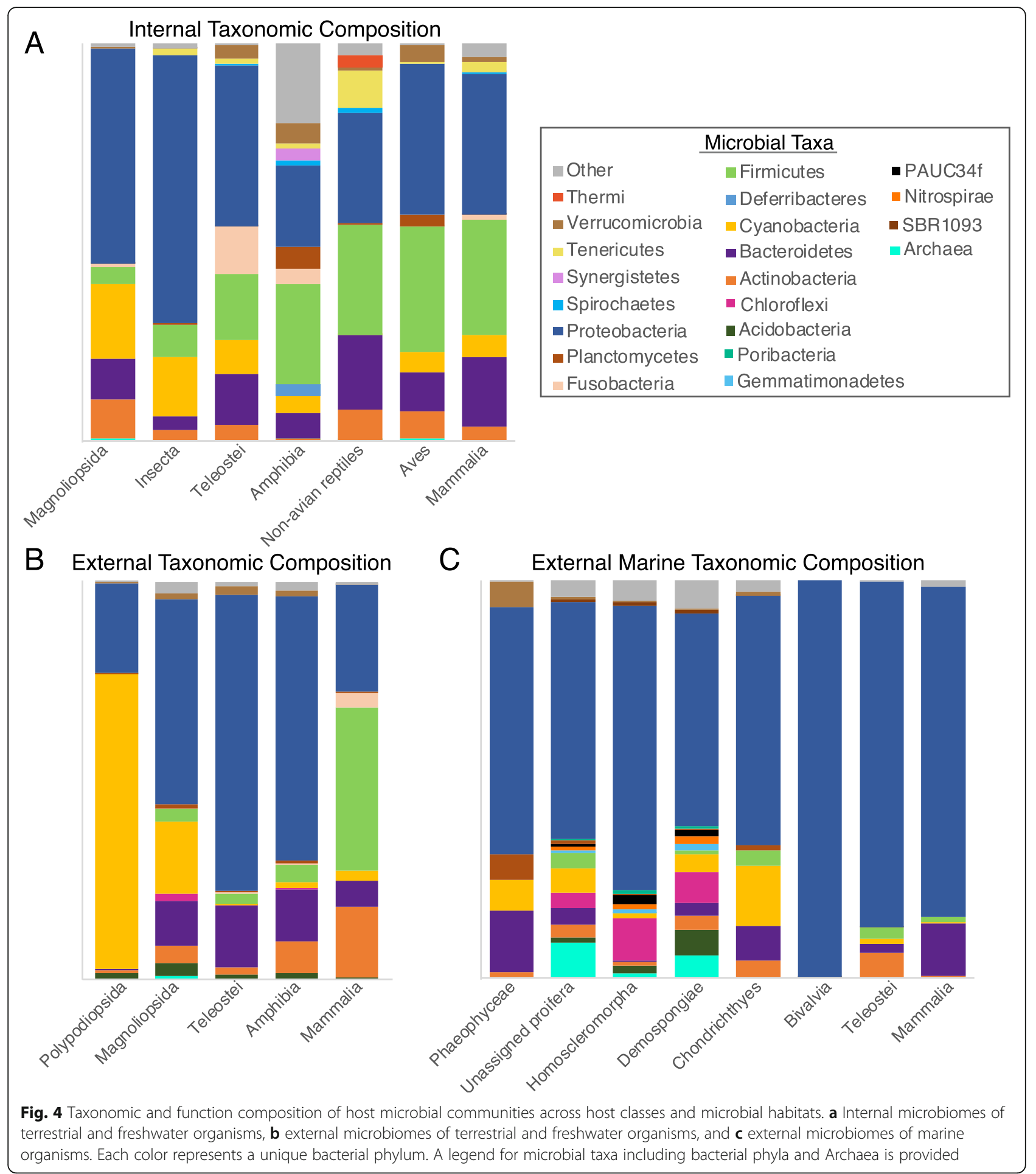

indirect path from host phylogeny through immune complexity (Fig. 9).

Our analysis revealed that internal (digestive-associated) microbiome diversity was predominantly shaped by host factors, while external (surface-associated) microbiome diversity was strongly associated with normalized difference vegetation index (NDVI) and some climatic factors such as precipitation of the warmest quarter (Bioclim18; Fig. 5). Similarly, a recent study of amphibian skin microbiomes found higher diversity on hosts in environments with colder winters and less stable thermal conditions (i.e., temperate regions [5];). Thus, increasing climatic variability appears to promote coexistence and diversity of external microbiomes, perhaps through ecological succession 


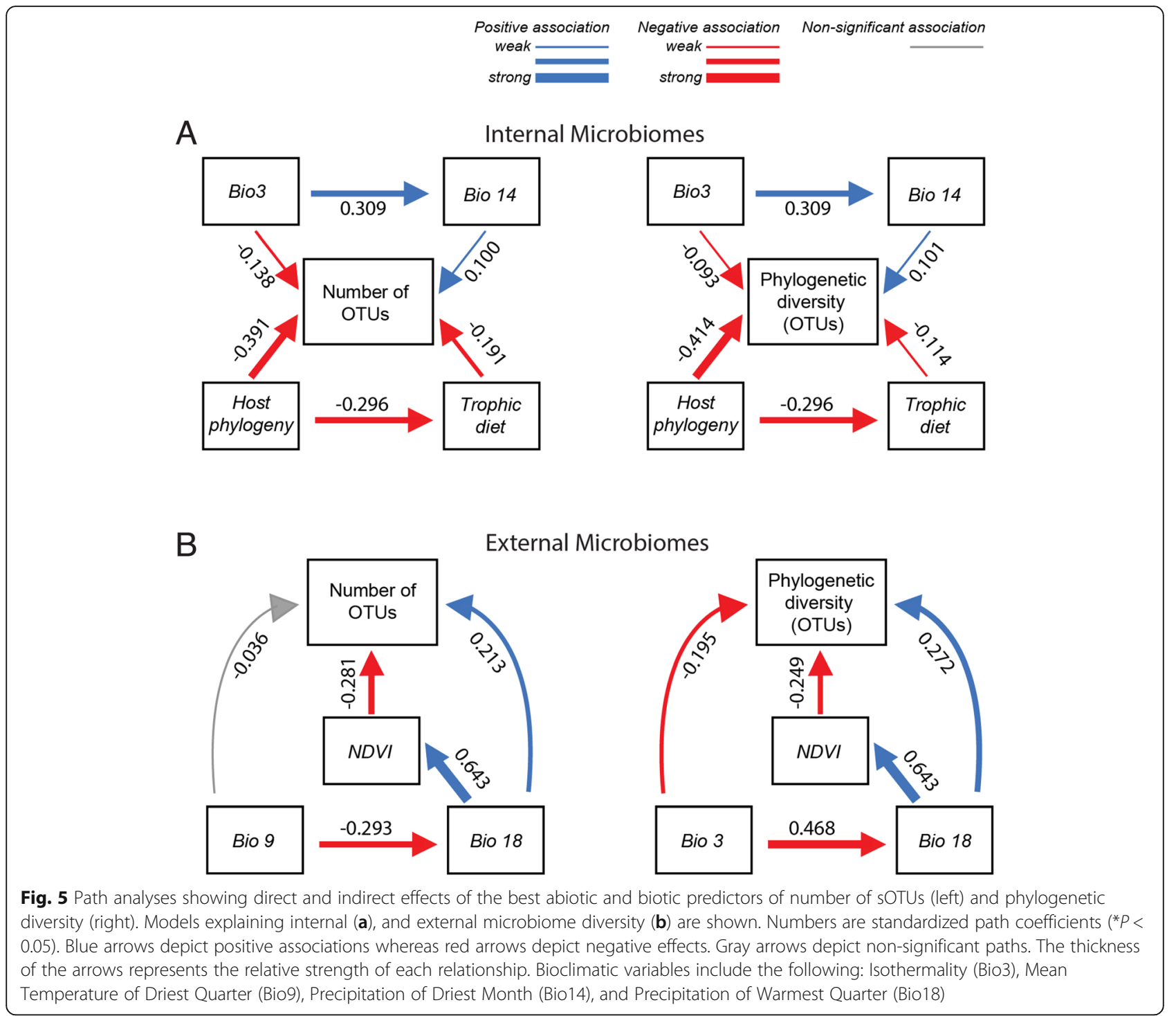

or dormancy mechanisms [5]. Nottingham et al. [69] found that both plant diversity and soil microbiome diversity follow temperature (and elevation) gradients at a regional scale with more species under warmer conditions. At a global scale, the external plant microbiome richness was also negatively correlated with elevation (Pearson's correlation, $N=85, r=-0.324, P=0.002$ ), but mean annual temperature was not significantly correlated with these plant microbiomes $(r=-0.174, P=0.111)$. Path analysis of our external microbiome dataset containing 33 plant host species did not show a significant effect of temperature on microbiome richness, but rather greater diversity with lower NDVI (Fig. 5). While host factors did not play a significant role in external microbiomes at the global scale, they can be important divers of host microbiomes locally (e.g., [70]).
Internal microbiome diversity was most strongly driven by host factors including host phylogeny and, to a weaker extent, diet or trophic level (Figs. 4, 5, and 6). Similarly, a study focused on non-human primates found that host phylogeny had a larger impact than dietary niche on gut microbiomes [33]. This finding is also supported by studies in other taxa including larval amphibians and aquatic invertebrates [71]. Previous studies found a more prominent role of host diet in shaping the gut microbiome [72, 73], particularly within clades such as lizards [74], fish [32, 67, 75], birds [76, 77], or mammals [78]. Captivity may produce bottom-up effects on microbiomes by altering environmental conditions and diets from field conditions [41]. Our data mirror macroecological patterns (e.g., Paine's keystone predation [79];) and suggest that bottomup processes of nutrient conditions shaped by host diet 


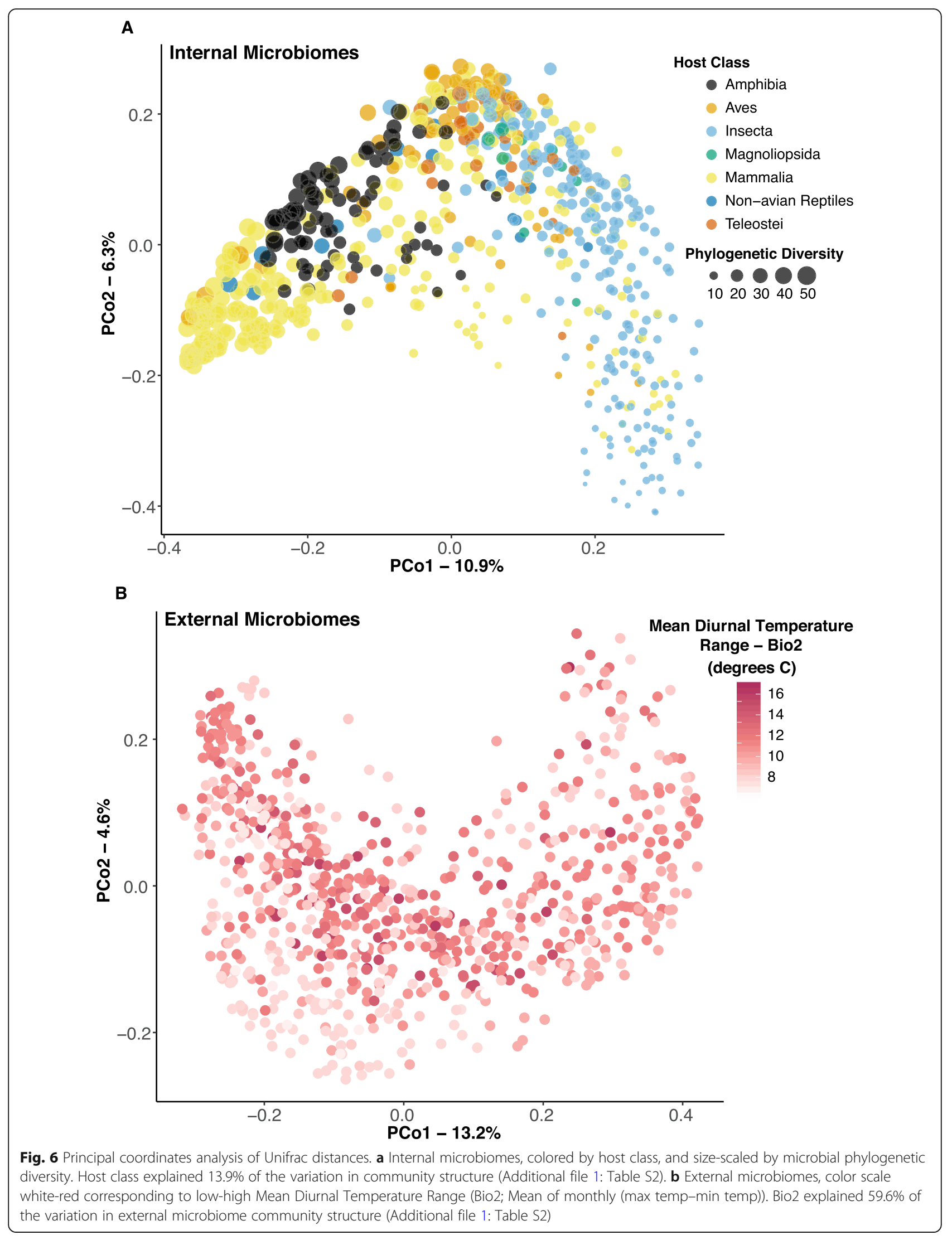




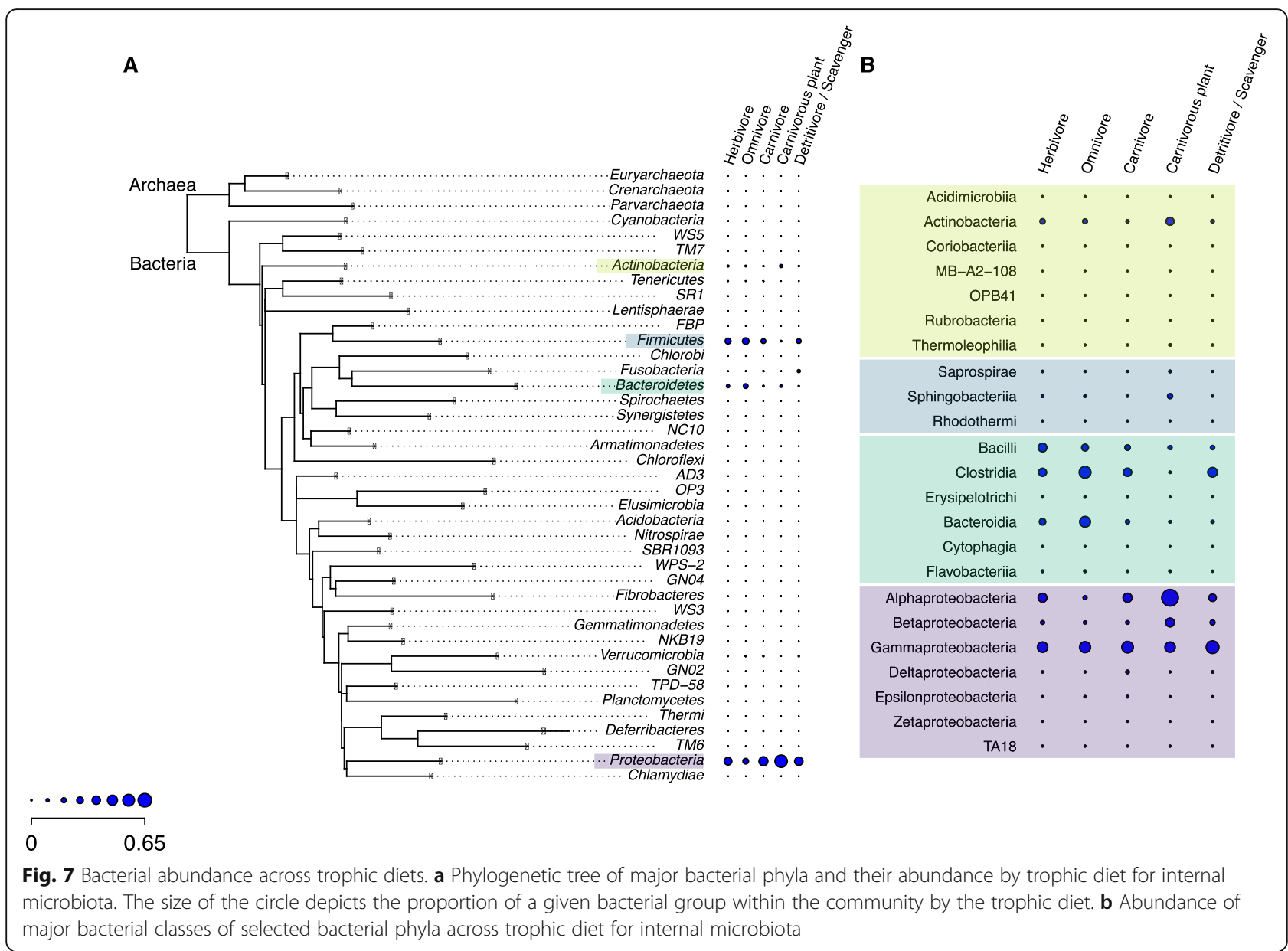

have weaker effects on microbiome diversity and structure than do the top-down processes of host physiology and immune function. Just as abiotic factors can influence or reverse top-down effects of predators on ecosystem function [80], the relative strength of host immune function may be similarly disrupted (e.g., antibiotics, immunocompromise) and have strong influences on the host microbiome ([15, 17, 31]; Table 1).

Host immune systems are thought to function in reducing microbes, commonly maligned as germs. We found, perhaps counterintuitively, that a greater diversity of bacteria are hosted by organisms with more complex adaptive immune systems (Figs. 8 and 9). Indeed, we would add to Mcfall-Ngai's [1] prescient framework quoted above and suggest that core bacteria that are more abundant in organisms with exclusively innate immunity may trade off this stability with more complex immune function during the evolution of adaptive immunity [68]. Indeed, top-down effects of immune function may be analogous to predation effects and promote maintenance of diversity by decreasing competition and allowing coexistence [79]. Understanding these patterns may encourage forward thinking responses to current environmental impacts affecting microbiome evolution and host health ([81, 82]; Table 1$)$.

\section{Conclusions}

Several reviews have highlighted the need for standardized data collection methods and greater taxonomic breadth and sampling of wild hosts, considered the least investigated compared with domestic and model host species $[67,81,83]$. Wild hosts may provide the greatest insight on host evolutionary biology and ecology, since captivity can have dramatic impacts on the microbiome [41, 42]. Understanding how host-associated microbiomes are naturally assembled and influenced by abiotic and host conditions provides insight on potential reservoirs of microbiota and can inform metacommunity models that predict community structure and transmission of microbes or dispersal and feedback between hosts and habitats $[44,84]$. While there remain wide geographical (Fig. 1) and taxonomic gaps (Fig. 3) in host-microbiome studies, our large sample set enabled the description of global-scale patterns in both internal (gut and reproductive tract) as well as external surface (leaves, skin, gill) microbiomes. Using a standardized 

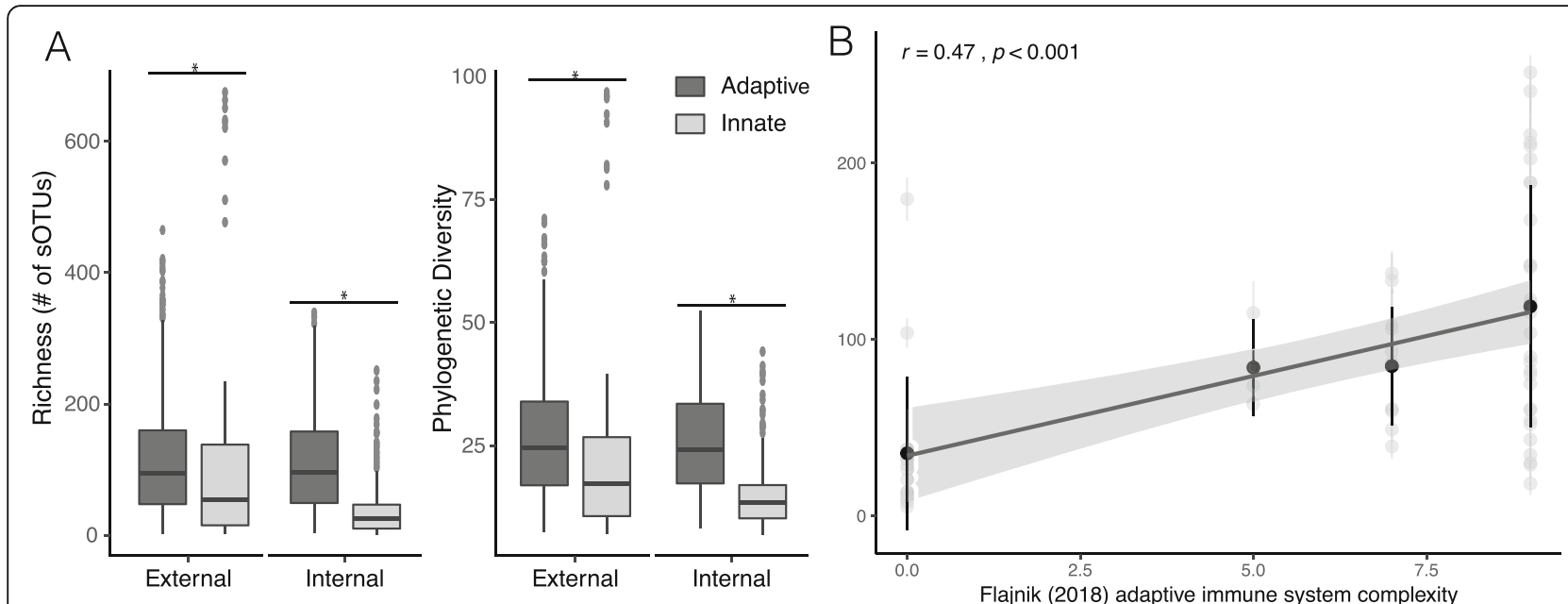

Fig. 8 Immune system complexity associations with diversity of host microbiomes. a Mean richness and phylogenetic diversity (external and internal microbiomes) for host genera with adaptive immune systems is significantly greater than host genera with only innate immunity. ${ }^{*} P<$ 0.001, Wilcoxon tests. $\mathbf{b}$ Mean internal sOTU richness correlates with adaptive immune system complexity based on the Flajnik [68] comparative immunology scale (see Additional file 1: Table S3)

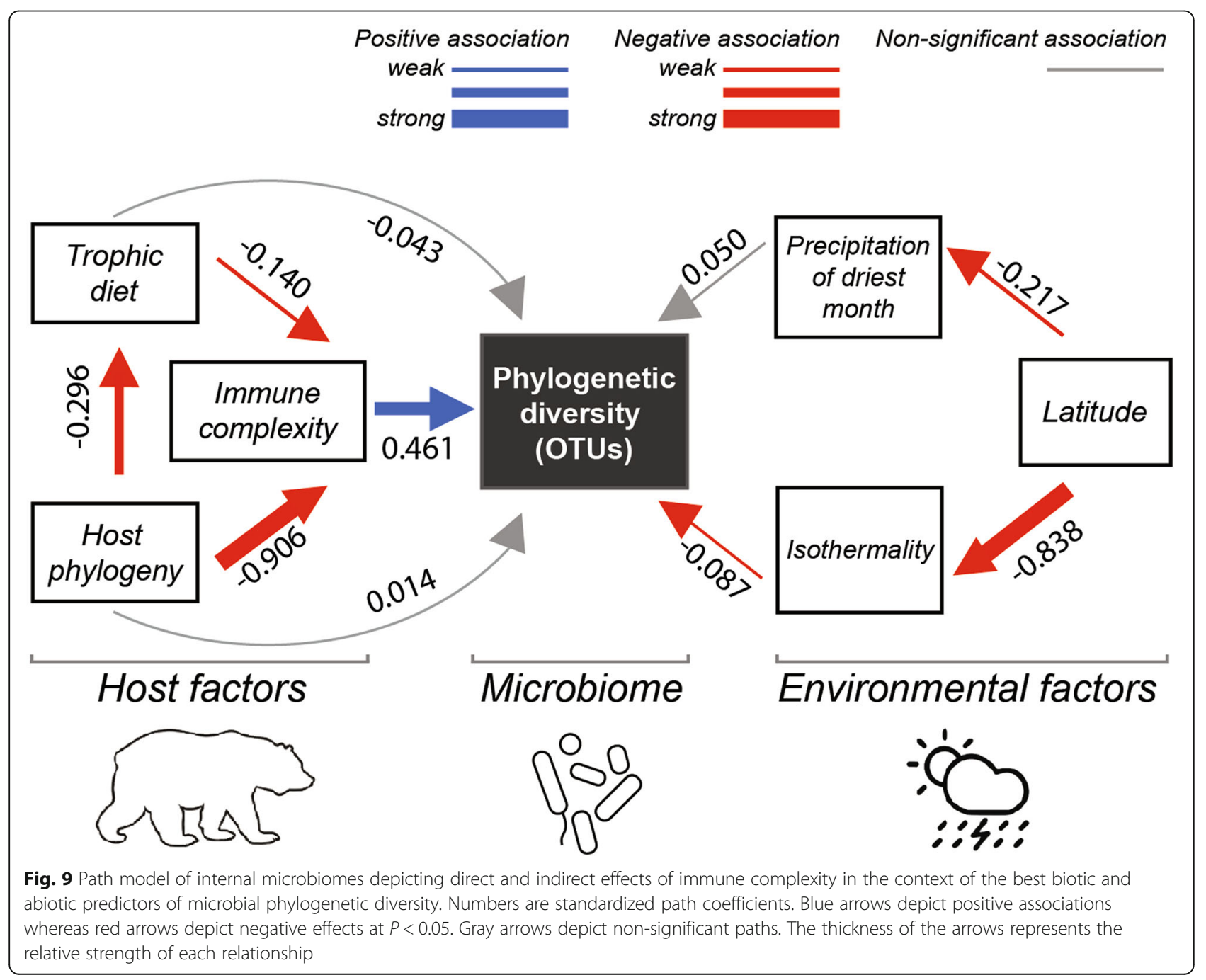


Table 3 Taxonomic classes with positive detection of Wolbachia-specific sOTUs

\begin{tabular}{llll}
\hline Taxonomic class & Average reads per sample & $\begin{array}{l}\text { Number of unique Wolbachia sOTUs } \\
\text { within class (total = 33) }\end{array}$ & $\begin{array}{l}\text { Percentage of Wolbachia sOTUs } \\
\text { found in Insecta }^{c}\end{array}$ \\
\hline Amphibia & 0.131 & 12 & 41.7 \\
Demospongiae & 0.007 & 1 & 100.0 \\
Insecta & 33.305 & 23 & 100.0 \\
Magnoliopsida & 0.024 & 1 & 0.0 \\
Mammalia & 0.002 & 4 & 75.0 \\
Phaeophyceae & 0.003 & 1 & 100.0
\end{tabular}

${ }^{a}$ Insecta had a substantially higher number of average Wolbachia reads than any other class. Most other Wolbachia-positive samples were rare and found in organisms where insects are a substantial portion of the diet (e.g., amphibia, bats, carnivorous plants), and as some of the host samples were derived from the gut, this is to be expected. Interestingly, Demospongiae were positive for Wolbachia, which may indicate that there were marine arthropods living within the sponges that were Wolbachia-positive

${ }^{\mathrm{b}}$ Insecta showed the highest number of unique Wolbachia sOTUs present within each class. Amphibia was high in the number of unique sOTUs, and many of these amphibian samples were taken from the gut

${ }^{c}$ Calculating the relative percentage of sOTUs found within each class that are also found within class Insecta indicated that the majority of sOTUs attributed to other host samples can be found in Insecta (likely as part of the diet of the host), and the remaining sOTUs are likely insects that are not present as directly collected samples in the dataset that were also prey items to their hosts. A heatmap showing mean abundance of each Wolbachia sOTU is presented in Additional file 1: Figure S8

approach, we found compelling evidence that internal vs. external microbiomes differ in the predominant factors associated with diversity and composition. Our analysis also revealed several correlations that at first glance were counterintuitive, such as microbiome diversity increasing with host immune system complexity, that suggest previously unrecognized top-down regulating effects. The analysis of Wolbachia occurrence and diversity across hosts and environments exemplifies the data mining potential of the metadata set assembled for this study. We anticipate that the identified patterns will be instrumental in deriving testable hypotheses and therefore have great potential to stimulate exciting experimental tests to elucidate the underlying mechanisms.

\section{Methods \\ Sequence acquisition}

To investigate global patterns of microbiome diversity and structure across host systems, we performed standardized bioinformatics analysis on combined datasets and procured environmental and host-associated metadata. We focused on studies with targeted 16S rRNA gene sequence data obtained from an Illumina platform.

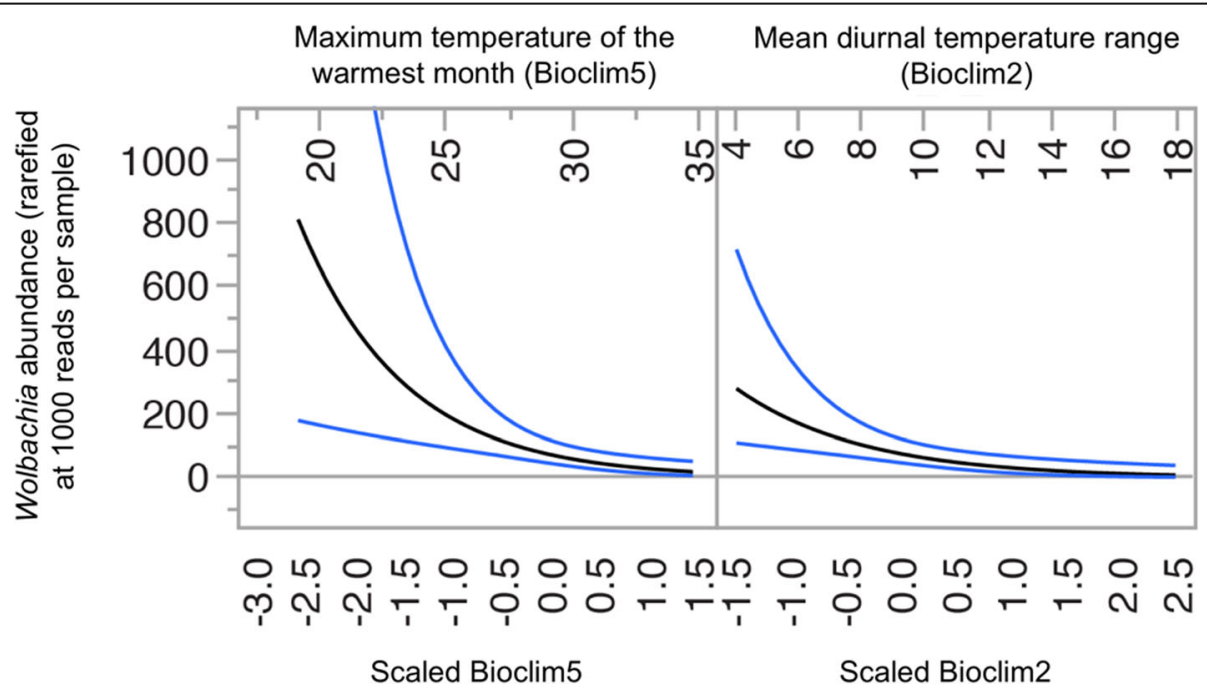

Fig. 10 Wolbachia in insects are globally diverse and decrease in abundance with temperature range. Maximum temperature of the warmest month (Bioclim5) and mean diurnal temperature range (Bioclim2) negatively predict relative Wolbachia abundance in samples derived from insects. Blue lines indicate 95\% confidence limits. Details can be found in Additional file 1: Figure S8. This is one example of how this global microbiome dataset can be used to better understand and analyze host-microbe interactions 
A literature search was conducted to identify relevant studies with data accessible from public databases. The majority of sample sequences were downloaded from the Sequence Read Archive (SRA) of the National Center for Biotechnology Information (NCBI), the European Nucleotide Archive (ENA), MG-RAST, and Qiita repositories. The combined dataset is made available here (Additional file 2, 3, 4, 5, 6, 7, 8, 9, 10, 11, and 12), and accession numbers and DOIs for all published studies are indicated in the mapping (metadata) files described in Additional file 1.

Datasets were selected that followed the Earth Microbiome Project (EMP) protocols and standards (http:// www.earthmicrobiome.org/protocols-and-standards/).

Studies were first screened to ensure certain criteria were met, including (1) collected from a "wild setting," where hosts were not exposed to any experimental treatments; (2) ethanol preserved or frozen until DNA extraction; (3) targeted the V4 region of the 16S rRNA bacterial gene region, using primers $515 \mathrm{f}$ and 806r [85]; and (4) sequencing on Illumina MiSeq or Illumina HiSeq platforms. Once a study passed our inclusion filters, we downloaded fastq files and obtained metadata for each study. The compiled dataset is comprised of 15,790 samples from 51 studies including all host-associated data from the Earth Microbiome Project [4] and includes 16 host classes (Fig. 3) from plants to corals to vertebrates (including 4 human populations; Additional file 1: Figure S4, $[9,50-58,85-121])$.

\section{Sequence preparation}

Sequence data were quality filtered using Quantitative Insights into Microbial Ecology (QIIME) defaults and classified into sub-Operational Taxonomic Units (sOTUS, or unique sequence variants) using the Deblur workflow [27]. Within Deblur, reads were trimmed to $90 \mathrm{bp}$ to correspond with the shortest read length in the combined dataset. Taxonomy was assigned using the RDP Classifier with GreenGenes $13-8$ as reference through a custom bash script [122, 123]. Then, sOTUs with fewer than 90 reads, taxonomically assigned as "mitochondria" and "chloroplast," or not identifiable at the Kingdom level were removed. A phylogenetic tree was built with fasttree2 [124]. Samples were rarefied at 1000 sequences per sample to retain most samples, normalize read counts across samples, and reduce computational demands. Furthermore, we standardized sampling across locations and host species by randomly selecting up to 10 samples from a given host species at a given country (see Table 2 for overall sample sizes and number of unique sOTUs). Datasets before and after processing as described above can be found in the Additional files.

\section{General analysis framework and datasets}

We employed multiple statistical approaches, including general linearized models, permutational multivariate analysis of variance, and path models, to explore the main drivers of host-associated microbial diversity, community structure (i.e., beta diversity), and PICRUStpredicted functionality. Tests also targeted hypotheses surrounding how immune function may shape diversity and composition of host microbiomes and how the distribution of Wolbachia varies across bioclimates.

For our analyses, the data were divided into 3 main subsets: (i) an internal microbiome dataset comprised of 741 samples derived from internal host habitats or whole-body samples, (ii) an external microbiome dataset comprised of 1193 samples derived from external host surfaces, and (iii) a marine dataset comprised of 266 external surface samples from marine organisms. Table 2 provides detailed information on sample types included in each dataset. The geographic distribution of these samples is depicted in Fig. 1. Additional data files for each subset are provided as indicated in Additional file 1.

\section{Sample metadata and predictor variables}

For each sample, we tabulated a comprehensive set of abiotic and biotic predictor variables for testing targeted hypotheses and inclusion in model-based analyses of our datasets. Associated metadata included in the mapping file was gathered by downloading the metadata for each study, taken directly from the paper corresponding to the study, or obtained from publicly available databases. Table 2 provides a description of each metadata field.

Elevation data was extracted from Google Earth using latitude/longitude coordinates. Current bioclimatic variables representing temperature and precipitation $(1 \mathrm{~km}$ resolution) were extracted for each unique geographic location from the WorldClim2 database. These 19 bioclimatic variables were extrapolated from a global network of stations collecting data from 1970 to 2000 [125]. Eighteen marine and geophysical variables were extracted from the MARSPEC database at the same $1 \mathrm{~km}$ resolution [126] for the marine dataset models. The variables of interest are defined in Additional file 1: Table S1 and below. Because of expected high correlation between many Worldclim bioclimatic variables, we filtered these predictors to a least correlated subset. From the 19 bioclim variables, we selected the 8 least correlated ones (caret package in R [127]) based on a threshold of $r<$ 0.7. These least correlated variables included Mean Diurnal Temperature Range (Bio2), Isothermality (Bio3), Max Temperature of Warmest Month (Bio5), Mean Temperature of Driest Quarter (Bio9), Precipitation of Driest Month (Bio14), Precipitation Seasonality (Bio15), Precipitation of Warmest Quarter (Bio18), and Precipitation of Coldest Quarter (Bio19) and were included in 
model selection procedures described below. The same procedure was performed for the 18 marine biophysical predictors resulting in the following least correlated subset: bathymetry, east/west aspect (biogeo1), north/south aspect (biogeo2), plane curviture (biogeo3), distance to shore (biogeo5), bathymetric slope (biogeo6), concavity (biogeo7), sea surface salinity of the saltiest month (biogeo10), annual variance of sea surface salinity (biogeo12), sea surface temperature of warmest month (biogeo15), and annual range of sea surface temperature (biogeo16).

Biotic predictors included host identity (host class or host phylogeny), host trophic diet (for internal dataset), external surface type, and immune system complexity. Either host class or a numeric nMDS proxy of host phylogeny was used to represent host identity. Host class information was obtained from the Encyclopedia of Life database (https://eol.org/). The host phylogeny proxy was created via the following steps. First, using timetree. org, we recovered a time-calibrated phylogenetic tree of host species represented in our study [128]. Second, patristic pairwise distances, i.e., branch lengths separating taxa, were then calculated with the Ape and Adephylo packages in $R[129,130]$. Third, we performed nonmetric multidimensional scaling (nMDS), constrained to one dimension, on the patristic distance matrix in SPSS v24 (IBM Corp, Armonk, NY, USA) to create a univariate host phylogeny variable for use in model-based analyses. The nMDS proxy phylogeny variable was chosen because it captured the phylogenetic relationships among hosts and is a numeric variable available for path analyses. Host trophic diet levels was estimated based on the diet category, including primary producers (level 0 ), herbivores (1), omnivores (2), carnivores (3), and scavengers/detritivores (4). External surface type information was obtained from data available with sequence archives and the published papers. Immune system complexity was estimated in two ways: (i) as a binary categorical variable indicating whether the host possessed an adaptive or innate only immune system, and (ii) as an ordinal scale derived from immune system characteristics from Flajnik [68] (Additional file 1: Table S3).

\section{Analysis of alpha diversity}

Model selection procedures implementing generalized linear models (GLMs) and comprehensive path models were used to analyze alpha diversity for each of our datasets. We performed GLM model selection procedures to identify which of our main biotic and abiotic variables best predicted richness, measured as number of sOTUs and Faith's Phylogenetic Diversity for each of our three main datasets. More specifically, for internal, external, and marine microbiomes, we screened a total of 25 explanatory variables, including host phylogeny/ identity, trophic diet (internal only), external habitat types (marine only), absolute latitude, elevation, normalized index vegetation index (NDVI; external only), 8 least cross-correlated bioclimatic variables (internal and external only), and 11 least cross-correlated ocean biophysical variables (marine only; see above for least correlated sets). Competing models were ranked based on the Akaike Information Criterion (AIC), and we reported the most parsimonious model for each of our three datasets for each response variable. Multicollinearity was evaluated in each of the final models using the variance inflation factor (VIF) calculated with car package [131] in R.

We applied path analyses with maximum Wishart likelihood (500 iterations) to test for the relative strength of direct and indirect associations among abiotic/biotic predictors and microbiome diversity of our internal and external microbiome datasets. Path models were not built for the marine dataset due to low predictive power of included variables in the GLM model selection. We built models including the most parsimonious set of explanatory variables predicting microbiome diversity according to our GLM model selection procedures (see above). Our four path models explaining number of OTUs and Faith's Phylogenetic Diversity for both internal and external microbiomes included all ecologically meaningful associations among predictor variables. We performed a fifth path model for Faith's Phylogenetic Diversity of internal microbiomes, including direct and indirect effects of immune system complexity in the analysis. We reported whole model fit for our path models using the root-mean square error of approximation (RMSEA). When goodness of fit threshold for was not met (RMSEA $\leq 0.1$ ), we sequentially removed the weakest paths until minimum RMSEA threshold was met for each model. Analyses were performed using RAMONA platform in SYSTAT 13.2 [132].

\section{Analysis of beta diversity}

We performed permutational multivariate analysis of variance (PERMANOVA) to analyze microbial beta diversity and identify abiotic and biotic parameters influencing internal, external, and marine microbiomes. Weighted and unweighted Unifrac distances were calculated in QIIME, and PERMANOVA models were implemented in $\mathrm{R}$ with the adonis2() function in the vegan package [133]. Independent models were run for the internal, external, and marine datasets. Predictor variables included in beta diversity models were hypothesis-driven and included all variables from the best alpha diversity model for the given dataset as well as selected biotic factors. We visualized overarching patterns in microbial beta diversity through principal coordinates analysis using ggplot2 in R. 
Additionally, we visualized the microbial abundance of major bacterial phyla across host trophic diets. A phylogenetic tree, OTU table, and taxonomy table generated in QIIME were consolidated in R script using the phyloseq and ape packages [129, 134]. The function "dotTree" from the R package phytools [135] was used to generate the phylogenetic tree at the phylum level. Microbial abundance of each phylum and the most abundant classes was calculated for each trophic diet level.

\section{Functional analysis with PICRUSt}

Phylogenetic Investigation of Communities by Reconstruction of Unobserved States (PICRUSt) predicts metagenomic function using marker gene (such as 16S rRNA) surveys [21]. GreenGenes 13-5 OTU IDs are required for PICRUSt analyses; therefore, we clustered our internal microbiome dataset sOTUs to Greengenes OTU IDs at 97\% similarity in QIIME. A custom R script was used to combine these GG IDs with abundance information to create a PICRUSt-formatted OTU table. We then performed the following steps: normalization by copy number, metagenome prediction, and consolidation of predictions into KEGG pathways. Results were filtered to retain data with an NSTI score of 0.06 or lower; 247 internal samples were represented in the final analysis. Nearest Sequenced Taxon Index (NSTI) is a confidence measure for PICRUSt predictions. Beta diversity calculations (Bray-Curtis and Jaccard dissimilarity) on PICRUSt functional predictions were performed in QIIME and analyzed in R using the adonis2 function from vegan. The PICRUSt package is available at http://picrust.github.io/picrust/.

\section{Analyses on immune system complexity}

We assessed the effect of immune system complexity on microbial diversity by (a) comparing sOTU richness and phylogenetic diversity between samples from hosts with adaptive vs. innate only immune systems for both the internal and external dataset-pairwise comparisons were implemented with Wilcoxon tests in R; (b) performing a correlation test between microbial richness and immune complexity using Kendall Tau correlation statistics in R; and (c) running our comprehensive path model including the immune complexity scale variable derived from Flajnik [68].

\section{Supplementary information}

Supplementary information accompanies this paper at https://doi.org/10. 1186/s13059-019-1908-8.

Additional file 1. Supplementary tables and figures [136-158].

Additional file 2. Full metadata file (15,790 samples), unfiltered.

Additional file 3. Filtered metadata file for internal microbiomes (741 samples).
Additional file 4. Filtered metadata file for external microbiomes (1193 samples).

Additional file 5. Filtered metadata file for marine external microbiomes (266 samples).

Additional file 6. Deblur sOTU table (biom file) for the full dataset, not rarefied.

Additional file 7. Deblur sOTU table (biom file) for the internal microbiome (741 samples), rarefied to $1000 \mathrm{reads} / \mathrm{sample.}$

Additional file 8. Deblur sOTU table (biom file) for the external microbiomes (1193 samples), rarefied to 1000 reads/sample.

Additional file 9. Deblur sOTU table (biom file) for the marine external microbiomes (266 samples), rarefied to 1000 reads/sample.

Additional file 10. RepSet fasta file for the full dataset.

Additional file 11. Fasta file to match OTU number with deblur sequence ID.

Additional file 12. Phylogenetic tree file used for analyses on data subsets.

Additional file 13. Review history.

\section{Acknowledgements}

This meta-analysis emerged from a graduate seminar at UMass Boston. We thank all the students that participated in the course.

Review history

The review history is available as Additional file 13.

\section{Peer review information}

Andrew Cosgrove was the primary editor on this article and managed its editorial process and peer review in collaboration with the rest of the editorial team

\section{Authors' contributions}

DCW initiated and led the project and coordinated and assisted with the data analysis. MCB trained the students in microbiome analysis, helped coordinate the project, and assisted with the statistical analyses. DCW, MB, $\mathrm{JK}$, and MV helped to conceptualize the bioclimatic analysis of the microbiome and PICRUSt datasets. The following authors were primarily responsible for various analyses: BL alpha-diversity analyses; GB path analyses; HD curated the mapping files, beta-diversity analyses; HB created the taxonomy plots; CL PICRUSt analyses; RH core analyses; DB GIS maps; GB, ATP, and JK Wolbachia analyses; PJK and RW host taxonomy plots; MV, KM, PJK, and NS data acquisition; and EK and KS microbial taxonomy plots. All authors contributed to writing the manuscript, and read and approved the final manuscript.

\section{Authors' information}

Twitter handle: @ATPsciencegirl (Amanda G. Tokash-Peters).

\section{Funding}

MCB was supported by a David H Smith Conservation Fellowship. JK was supported by Simons Foundation (429440, WTW). KS was supported by NSF DBI \#1759940. ATP was supported by the National Science Foundation grant DGE 1249946, the Integrative Graduate Education and Research Traineeship (IGERT): Coasts and Communities - Natural and Human Systems in Urbanizing Environments, and the University of Massachusetts SanofiGenzyme Doctoral Fellowship.

\section{Availability of data and materials}

The datasets supporting the conclusions of this article are included within the article and its Additional files (Additional file 2 through

Additional file 12). Additional file 1 provides descriptions of the data files (metadata, biom, fasta, and tree files). Links to DOI numbers and data repositories for each of the 51 datasets are indicated in Additional file 2. The data were described in the Earth Microbiome Project [4], the Global Amphibian Project [5], and additional recent studies referenced above. 


\section{Ethics approval and consent to participate}

Not applicable.

\section{Consent for publication}

Not applicable.

\section{Competing interests}

The authors declare that they have no competing interests.

\section{Author details}

'Department of Biology, University of Massachusetts Boston, Boston, MA 02125, USA. ${ }^{2}$ Smithsonian Tropical Research Institute, Roosevelt Ave. Tupper Building - 401, 0843-03092 Panamá, Panama. ${ }^{3}$ Department of Biological Sciences, The University of Alabama, Tuscaloosa, AL 35487, USA. ${ }^{4}$ School for the Environment, University of Massachusetts, Boston, MA 02125, USA. ${ }^{5}$ Animal Health Department, New England Aquarium, Boston, MA 02110, USA. ${ }^{6}$ Center of Excellence in Biodiversity and Natural Resource Management, University of Rwanda, RN1, Butare, Rwanda. 'Zoological Institute, Braunschweig University of Technology, Mendelssohnstr. 4, 38106 Braunschweig, Germany.

Received: 21 January 2019 Accepted: 2 December 2019

Published online: 03 February 2020

\section{References}

1. McFall-Ngai M. Care for the community. Nature. 2007:445:153.

2. Fierer N, Jackson RB. The diversity and biogeography of soil bacterial communities. Proc Natl Acad Sci U S A. 2006;103:626-31.

3. Lozupone CA, Knight R. Global patterns in bacterial diversity. Proc Natl Acad Sci U S A. 2007:104:11436-40

4. Thompson L, Sanders J, McDonald D, Amir A, Ladau J, Locey K, et al. A communal catalogue reveals Earth's multiscale microbial diversity. Nature. 2017:551:457.

5. Kueneman JG, Bletz MC, Mckenzie VJ, Becker CG, Joseph MB, Abarca JG, et al. Community richness of amphibian skin bacteria correlates with bioclimate at the global scale. Nat Ecol Evol. 2019;3:381-9.

6. Ley RE, Lozupone CA, Hamady M, Knight R, Gordon Jl. Worlds within worlds: evolution of the vertebrate gut microbiota. Nat Rev Microbiol. 2008; 6:776-88.

7. Bahram M, Hildebrand F, Forslund SK, Anderson JL, Soudzilovskaia NA, Bodegom PM, et al. Structure and function of the global topsoil microbiome. Nature. 2018;560:233-7.

8. Frey-Klett $P$, Burlinson $P$, Deveau $A$, Barret $M$, Tarkka $M$, Sarniguet $A$ Bacterial-fungal interactions: hyphens between agricultural, clinical, environmental, and food microbiologists. Microbiol Mol Biol Rev. 2011;75: 583-609.

9. Kueneman JG, Woodhams DC, Van Treuren W, Archer HM, Knight R, McKenzie VJ. Inhibitory bacteria reduce fungi on early life stages of endangered Colorado boreal toads (Anaxyrus boreas). ISME J. 2016:10:934-44.

10. Kearns PJ, Fischer S, Fernández-beaskoetxea S, Gabor CR, Zoological N, Si P. Fight fungi with fungi: antifungal properties of the amphibian mycobiome. Front Microbiol. 2017:8:1-12.

11. García-Bayona L, Comstock LE. Bacterial antagonism in host-associated microbial communities. Science. 2018;361:eaat2456.

12. Bosch TCG, Guillemin K, MCFall-Ngai M. Evolutionary "experiments" in symbiosis: The study of model animals provides insights into the mechanisms underlying the diversity of host-microbe interactions. BioEssays. 2019:41:e1800256.

13. Blaser M, Bork P, Fraser C, Knight R, Wang J. The microbiome explored: recent insights and future challenges. Nat Rev Microbiol. 2013:11:213.

14. McFall-Ngai M, Hadefield M, Bosch TCG, Carey HV, Domazet-Lošo T, Douglas $A E$, et al. Animals in a bacterial world, a new imperative for the life sciences. Proc Natl Acad Sci U S A. 2013:110:3229-36.

15. Zaneveld JR, McMinds R, Thurber RV. Stress and stability: applying the Anna Karenina principle to animal microbiomes. Nat Microbiol. 2017:2:17121.

16. Petersen C, Round JL. Defining dysbiosis and its influence on host immunity and disease. Cell Microbiol. 2014;16:1024-33.

17. Song SJ, Woodhams DC, Martino C, Allaband C, Mu A. Engineering the microbiome for animal health and conservation. Exp Biol Med. 2019; 244:494-504.
18. Nelson TM, Apprill A, Mann J, Rogers TL, Brown MV. The marine mammal microbiome: current knowledge and future directions. Microbiol Aust. 2015; 36:8-13.

19. Blaser MJ. The theory of disappearing microbiota and the epidemics of chronic diseases. Nat Rev Immunol. 2017;17:461-3.

20. Wellington EMH, Berry A, Krsek M. Resolving functional diversity in relation to microbial community structure in soil: exploiting genomics and stable isotope probing. Curr Opin Microbiol. 2003;6:295-301.

21. Langille MG, Zaneveld J, Caporaso JG, McDonald D, Knights D, Reyes JA, et al. Predictive functional profiling of microbial communities using $16 \mathrm{~S}$ rRNA marker gene sequences. Nat Biotechnol. 2013;31:814-21.

22. Legrand TPRA, Catalano SR, Wos-Oxley ML, Stephens F, Landos M, Bansemer MS, et al. The inner workings of the outer surface: skin and gill microbiota as indicators of changing gut health in yellowtail kingfish. Front Microbiol. 2018;8:2664

23. Glasl B, Herndl GJ, Frade PR. The microbiome of coral surface mucus has a key role in mediating holobiont health and survival upon disturbance. ISME J. 2016;10:2280

24. Stroup DF, Berlin JA, Morton SC, Olkin I, Williamson GD, Rennie D, et al. Meta-analysis of observational studies in epidemiology: a proposal for reporting. JAMA. 2000:283:2008-12.

25. Dubilier N, McFall-Ngai M, Zhao L. Microbiology: create a global microbiome effort. Nat News. 2015:526:631.

26. Alivisatos AP, Blaser MJ, Brodie EL, Chun M, Dangl JL, Donohue TJ, et al. A unified initiative to harness Earth's microbiomes. Science. 2015;350:507-8.

27. Amir A, McDonald D, Navas-Molina JA, Kopylova E, Morton JT, Zech Xu Z, et al. Deblur rapidly resolves single-nucleotide community sequence patterns. mSystems. 2017;2:e00191-16.

28. Turnbaugh PJ, Ley RE, Hamady M, Fraser-Liggett CM, Knight R, Gordon Jl. The human microbiome project. Nature. 2007:449:804.

29. Koren O, Knights D, Gonzalez A, Waldron L, Segata N, Knight R, et al. A guide to enterotypes across the human body: meta-analysis of microbial community structures in human microbiome datasets. PLoS Comput Biol. 2013;9:e1002863.

30. Lozupone C, Stombaugh J, Gonzalez A, Ackermann G, Wendel D, VázquezBaeza Y, et al. Meta-analyses of studies of the human microbiota. Genome Res. 2013;23:1704-1714.

31. Kriss M, Hazleton KZ, Nusbacher NM, Martin CG, Lozupone CA. Low diversity gut microbiota dysbiosis: drivers, functional implications and recovery. Curr Opin Microbiol. 2018:44:34-40.

32. Sullam KE, Essinger SD, Lozupone CA, O'Connor MP, Rosen GL, Knight ROB, et al. Environmental and ecological factors that shape the gut bacterial communities of fish: a meta-analysis. Mol Ecol. 2012;21:3363-78.

33. Amato KR, Sanders JG, Song SJ, Nute M, Metcalf $J$, Thompson LR, et al. Evolutionary trends in host physiology outweigh dietary niche in structuring primate gut microbiomes. ISME J. 2018;13:576-87.

34. Waite DW, Taylor MW. Characterizing the avian gut microbiota: membership, driving influences, and potential function. Front Microbiol. 2014;5:223.

35. Wegener Parfrey L, Walters WA, Knight R. Microbial eukaryotes in the human microbiome: ecology, evolution, and future directions. Front Microbiol. 2011:2:153.

36. Nash AK, Auchtung TA, Wong MC, Smith DP, Gesell JR, Ross MC, et al. The gut mycobiome of the Human Microbiome Project healthy cohort Microbiome. 2017:5:153.

37. Wolf YI, Kazlauskas D, Iranzo J, Lucía-Sanz A, Kuhn JH, Krupovic M, et al. Origins and evolution of the global RNA virome. MBio. 2018;9:e02329-18.

38. Hug LA, Baker BJ, Anantharaman K, Brown CT, Probst AJ, Castelle CJ, et al. A new view of the tree of life. Nat Microbiol. 2016;1:16048.

39. Lagier J-C, Dubourg G, Million M, Cadoret F, Bilen M, Fenollar F, et al. Culturing the human microbiota and culturomics. Nat Rev Microbiol. 2018; 16:540-50.

40. Huys GRB, Raes J. Go with the flow or solitary confinement: a look inside the single-cell toolbox for isolation of rare and uncultured microbes. Curr Opin Microbiol. 2018:44:1-8.

41. McKenzie VJ, Song SJ, Delsuc F, Prest TL, Oliverio AM, Korpita TM, et al. The effects of captivity on the mammalian gut microbiome. Integr Comp Biol. 2017;57:690-704.

42. Hird SM. Evolutionary biology needs wild microbiomes. Front Microbiol. 2017:8:1-10

43. Shade A, Dunn RR, Blowes SA, Keil P, Bohannan BJM, Herrmann M, et al. Macroecology to unite all life, large and small. Trends Ecol Evol. 2018;33:731-44 
44. Miller ET, Svanbäck R, Bohannan BJM. Microbiomes as metacommunities: understanding host-associated microbes through metacommunity ecology. Trends Ecol Evol. 2018;33:926-35.

45. Loudon AH, Venkataraman A, Van Treuren W, Woodhams DC, Parfrey LW, McKenzie VJ, et al. Vertebrate hosts as islands: dynamics of selection, immigration, loss, persistence, and potential function of bacteria on salamander skin. Front Microbiol. 2016;7:333.

46. Prest TL, Kimball AK, Kueneman JG, McKenzie VJ. Host-associated bacterial community succession during amphibian development. Mol Ecol. 2018;27:1992-2006

47. Bello MGD, Knight R, Gilbert JA, Blaser MJ. Preserving microbial diversity. Science. 2018;362:33-4.

48. Klassen JL. Defining microbiome function. Nat Microbiol. 2018;3:864

49. Project THM. Structure, function and diversity of the healthy human microbiome. Nature. 2012:486:207-14.

50. Kohl KD, Weiss RB, Cox J, Dale C, Dearing MD. Gut microbes of mammalian herbivores facilitate intake of plant toxins. Ecol Lett. 2014;17:1238-46.

51. Muhlebach MS, Zorn BT, Esther CR, Hatch JE, Murray CP, Turkovic L, et al. Initial acquisition and succession of the cystic fibrosis lung microbiome is associated with disease progression in infants and preschool children. PLoS Pathog. 2018;14:e1006798.

52. Kohl KD, Miller AW, Marvin JE, Mackie R, Dearing MD. Herbivorous rodents (Neotoma spp.) harbour abundant and active foregut microbiota. Environ Microbiol. 2014;16:2869-2878.

53. Stone BWG, Jackson CR. Biogeographic patterns between bacterial phyllosphere communities of the Southern Magnolia (Magnolia grandiflora) in a small forest. Microb Ecol. 2016;71:954-61.

54. Wang W, Cao J, Yang F, Wang X, Zheng S, Sharshov K, et al. High-throughput sequencing reveals the core gut microbiome of Bar-headed goose (Anser indicus) in different wintering areas in Tibet. Microb Open. 2016;5:287-95.

55. Sabino-Pinto J, Bletz MC, Islam MM, Shimizu N, Bhuju S, Geffers R, et al. Composition of the cutaneous bacterial community in Japanese amphibians: effects of captivity, host species, and body region. Microb Ecol. 2016;72:460-469

56. Amato KR, Martinez-Mota R, Righini N, Raguet-Schofield M, Corcione FP, Marini $E$, et al. Phylogenetic and ecological factors impact the gut microbiota of two Neotropical primate species. Oecologia. 2016;180:717-33.

57. Bletz MC, Vences M, Sabino-Pinto J, Taguchi Y, Shimizu N, Nishikawa K, et al. Cutaneous microbiota of the Japanese giant salamander (Andrias japonicus), a representative of an ancient amphibian clade. Hydrobiologia. 2017;795: $153-167$.

58. Sankaranarayanan K, Ozga AT, Warinner C, Tito RY, Obregon-Tito AJ, Xu J, et al. Gut microbiome diversity among Cheyenne and Arapaho individuals from western Oklahoma. Curr Biol. 2015;25:3161-9.

59. Hoffmann AA, Montgomery BL, Popovici J, Iturbe-Ormaetxe I, Johnson PH, Muzzi F, et al. Successful establishment of Wolbachia in Aedes populations to suppress dengue transmission. Nature. 2011;476:454.

60. McMeniman CJ, Lane RV, Cass BN, Fong AWC, Sidhu M, Wang Y-F, et al. Stable introduction of a life-shortening Wolbachia infection into the mosquito Aedes aegypti. Science. 2009;323:141-4.

61. Knight R, Vrbanac A, Taylor BC, Aksenov A, Callewaert C, Debelius J, et al. Best practices for analysing microbiomes. Nat Rev Microbiol. 2018:410-22.

62. Hammer TJ, Dickerson JC, Fierer N. Evidence-based recommendations on storing and handling specimens for analyses of insect microbiota. PeerJ. 2015;3:e1190.

63. Sender R, Fuchs S, Milo R. Revised estimates for the number of human and bacteria cells in the body. PLoS Biol. 2016;14:1-14.

64. Yatsunenko T, Rey FE, Manary MJ, Trehan I, Dominguez-bello MG, Contreras $\mathrm{M}$, et al. Human gut microbiome viewed across age and geography. Nature. 2012;486.

65. Joe JTX, Chiou PP, Kuo C-Y, Lin JHJ, Wu J-L, Lu M-W. The microbiota profile and transcriptome analysis of immune response during metamorphosis stages in orange spotted grouper (Epinephelus coioides). Fish Shellfish Immunol. 2019;90:141-149.

66. Yan Q, Li J, Yu Y, Wang J, He Z, Van Nostrand JD, et al. Environmental filtering decreases with fish development for the assembly of gut microbiota. Environ Microbiol. 2016;18:4739-54.

67. Egerton S, Culloty S, Whooley J, Stanton C, Ross RP. The gut microbiota of marine fish. Front. Microbiol. 2018;9:873.

68. Flajnik MF. A cold-blooded view of adaptive immunity. Nat Rev Immunol. 2018;7:438-53.
69. Nottingham AT, Fierer N, Turner BL, Whitaker J, Ostle NJ, McNamara NP, et al. Microbes follow Humboldt: temperature drives plant and soil microbial diversity patterns from the Amazon to the Andes. Bull Ecol Soc Am. 2019;100:1-4.

70. Chiarello M, Auguet J-C, Bettarel Y, Bouvier C, Claverie T, Graham NAJ, et al. Skin microbiome of coral reef fish is highly variable and driven by host phylogeny and diet. Microbiome. 2018;6:147.

71. Lyra ML, Bletz MC, Haddad CFB, Vences M. The intestinal microbiota of tadpoles differs from those of syntopic aquatic invertebrates. Microb Ecol. 2018;76:121-4.

72. Colston TJ. Gut microbiome transmission in lizards. Mol Ecol. 2017;26:972-4.

73. Steffan SA, Chikaraishi Y, Currie CR, Horn H, Gaines-Day HR, Pauli JN, et al. Microbes are trophic analogs of animals. Proc Natl Acad Sci U S A. 2015;112: 15119-24.

74. Kohl KD, Brun A, Magallanes M, Brinkerhoff J, Laspiur A, Acosta JC, et al. Gut microbial ecology of lizards: insights into diversity in the wild, effects of captivity, variation across gut regions and transmission. Mol Ecol. 2017;26:1175-89.

75. Liu H, Guo X, Gooneratne R, Lai R, Zeng C, Zhan F, et al. The gut microbiome and degradation enzyme activity of wild freshwater fishes influenced by their trophic levels. Sci Rep. 2016;6:24340.

76. Grond K, Sandercock BK, Jumpponen A, Zeglin LH. The avian gut microbiota: community, physiology and function in wild birds. J Avian Biol. 2018:49:e01788

77. Michel AJ, Ward LM, Goffredi SK, Dawson KS, Baldassarre DT, Brenner A, et al. The gut of the finch: uniqueness of the gut microbiome of the Galápagos vampire finch. Microbiome. 2018;6:167.

78. Ley RE, Hamady M, Lozupone C, Turnbaugh PJ, Ramey RR, Bircher JS, et al. Evolution of mammals and their gut microbes. Science. 2008;320:1647-51.

79. Terborgh JW. Toward a trophic theory of species diversity. Proc Natl Acad Sci U S A. 2015;112:11415-22.

80. Koltz AM, Classen AT, Wright JP. Warming reverses top-down effects of predators on belowground ecosystem function in Arctic tundra. Proc Natl Acad Sci U S A. 2018;115:E7541-9.

81. Colston TJ, Jackson CR. Microbiome evolution along divergent branches of the vertebrate tree of life: what's known and unknown. Mol Ecol. 2016;25:3776-800.

82. Davenport ER, Sanders JG, Song SJ, Amato KR, Clark AG, Knight R. The human microbiome in evolution. BMC Biol. 2017;15:127.

83. Pascoe EL, Hauffe HC, Marchesi JR, Perkins SE. Network analysis of gut microbiota literature: an overview of the research landscape in non-human animal studies. ISME J. 2017;11:2644-51.

84. Adair KL, Douglas AE. Making a microbiome: the many determinants of host-associated microbial community composition. Curr Opin Microbiol. 2017;35:23-9.

85. Caporaso JG, Lauber CL, Walters WA, Berg-lyons D, Lozupone CA, Turnbaugh PJ, et al. Global patterns of $16 \mathrm{~S}$ rRNA diversity at a depth of millions of sequences per sample. Proc Natl Acad Sci U S A. 2011; 108:4516-22.

86. Amato KR, Metcalf JL, Song SJ, Hale VL, Clayton J, Ackermann G, et al. Using the gut microbiota as a novel tool for examining colobine primate $\mathrm{Gl}$ health. Glob Ecol Conserv. 2016;7:225-37.

87. Hale $\mathrm{VL}$, Tan $\mathrm{CL}$, Knight $\mathrm{R}$, Amato KR. Effect of preservation method on spider monkey (Ateles geoffroyi) fecal microbiota over 8 weeks. J Microbiol Methods. 2015;113:16-26.

88. Smith CCR, Snowberg LK, Caporaso JG, Knight R, Bolnick DI. Dietary input of microbes and host genetic variation shape among-population differences in stickleback gut microbiota. ISME J. 2015;9:2515.

89. Wagner MR, Lundberg DS, Tijana G, Tringe SG, Dangl JL, Mitchell-Olds T. Host genotype and age shape the leaf and root microbiomes of a wild perennial plant. Nat Commun. 2016;7:12151.

90. Bates KA, Clare FC, O'Hanlon S, Bosch J, Brookes L, Hopkins K, et al. Amphibian chytridiomycosis outbreak dynamics are linked with host skin bacterial community structure. Nat Commun. 2018;9:693.

91. Lewis ZT, Sidamonidze K, Tsaturyan V, Tsereteli D, Khachidze N, Pepoyan A, et al. The fecal microbial community of breast-fed infants from Armenia and Georgia. Sci Rep. 2017;7:40932.

92. Hakim JA, Koo H, Kumar R, Lefkowitz EJ, Morrow CD, Powell ML, et al. The gut microbiome of the sea urchin, Lytechinus variegatus, from its natural habitat demonstrates selective attributes of microbial taxa and predictive metabolic profiles. FEMS Microbiol Ecol. 2016;92:146.

93. Moitinho-Silva L, Nielsen S, Amir A, Gonzalez A, Ackermann GL, Cerrano C, et al. The sponge microbiome project. Gigascience. 2017;6:gix077. 
94. Sanders JG, Łukasik P, Frederickson ME, Russell JA, Koga R, Knight R, et al. Dramatic differences in gut bacterial densities correlate with diet and habitat in rainforest ants. Integr Comp Biol. 2017;57:705-22.

95. Hammer TJ, Fierer N, Hardwick B, Simojoki A, Slade E, Taponen J, et al. Treating cattle with antibiotics affects greenhouse gas emissions, and microbiota in dung and dung beetles. Proc R Soc B Biol Sci. 2016;283: 20160150.

96. Raulo A, Ruokolainen L, Lane A, Amato K, Knight R, Leigh S, et al. Social behaviour and gut microbiota in red-bellied lemurs (Eulemur rubriventer): in search of the role of immunity in the evolution of sociality. J Anim Ecol. 2018:87:388-99.

97. Marzinelli EM, Campbell AH, Zozaya Valdes E, Vergés A, Nielsen S, Wernberg $T$, et al. Continental-scale variation in seaweed host-associated bacterial communities is a function of host condition, not geography. Environ Microbiol. 2015;17:4078-88.

98. Delsuc F, Metcalf JL, Wegener Parfrey L, Song SJ, González A, Knight R. Convergence of gut microbiomes in myrmecophagous mammals. Mol Ecol. 2014;23:1301-17

99. Yuan ML, Dean SH, Longo AV, Rothermel BB, Tuberville TD, Zamudio KR. Kinship, inbreeding and fine-scale spatial structure influence gut microbiota in a hindgut-fermenting tortoise. Mol Ecol. 2015;24:2521-36.

100. Toju H, Vannette RL, Gauthier ML, Dhami MK, Fukami T. Priority effects can persist across floral generations in nectar microbial metacommunities. Oikos. 2018;127:345-52.

101. Van Treuren W, Ponnusamy L, Brinkerhoff RJ, Gonzalez A, Parobek CM, Juliano JJ, et al. Variation in the microbiota of Ixodes ticks with regard to geography, species, and sex. Appl Environ Microbiol. 2015;81:6200-9.

102. Caporaso JG, Lauber CL, Costello EK, Berg-Lyons D, Gonzalez A, Stombaugh J, et al. Moving pictures of the human microbiome. Genome Biol. 2011;12:R50.

103. Koehler AV, Haydon SR, Jex AR, Gasser RB. Cryptosporidium and Giardia taxa in faecal samples from animals in catchments supplying the city of Melbourne with drinking water (2011 to 2015). Parasit Vectors. 2016;9:315.

104. Nolan MJ, Jex AR, Koehler AV, Haydon SR, Stevens MA, Gasser RB. Molecular-based investigation of Cryptosporidium and Giardia from animals in water catchments in southeastern Australia. Water Res. 2013;47:1726-40.

105. Zeng $Y$, Zeng D, Ni X, Zhu H, Jian P, Zhou Y, et al. Microbial community compositions in the gastrointestinal tract of Chinese Mongolian sheep using Illumina MiSeq sequencing revealed high microbial diversity. AMB Express. 2017;7:75.

106. Vences M, Lyra MML, Kueneman JG, Bletz MC, Archer HM, Canitz J, et al. Gut bacterial communites across tadpole ecomorphs in two diverse tropical anuran faunas. Sci Nat. 2016;103:25.

107. Piombino P, Genovese A, Esposito S, Moio L, Cutolo PP, Chambery A, et al. Saliva from obese individuals suppresses the release of aroma compounds from wine. PLoS One. 2014;9:e85611.

108. Apprill A, Robbins J, Eren AM, Pack AA, Reveillaud J, Mattila D, et al. Humpback whale populations share a core skin bacterial community: towards a health index for marine mammals? PLoS One. 2014;9:e90785.

109. Price JT, Paladino FV, Lamont MM, Witherington BE, Bates ST, Soule T. Characterization of the juvenile green turtle (Chelonia mydas) microbiome throughout an ontogenetic shift from pelagic to neritic habitats. PLoS One. 2017;12:e0177642

110. Whitaker MRL, Salzman S, Sanders J, Kaltenpoth M, Pierce NE. Microbial communities of lycaenid butterflies do not correlate with larval diet. Front Microbiol. 2016;7:1920

111. Novakova E, Woodhams DC, Rodríguez-Ruano SM, Brucker RM, Leff JW, Maharaj A, et al. Mosquito microbiome dynamics, a background for prevalence and seasonality of West Nile virus. Front Microbiol. 2017;8:526.

112. Jiang H-Y, Ma J-E, Li J, Zhang X-J, Li L-M, He N, et al. Diets alter the gut microbiome of crocodile lizards. Front Microbiol. 2017:8:2073.

113. Parris DJ, Brooker RM, Morgan MA, Dixson DL, Stewart FJ. Whole gut microbiome composition of damselfish and cardinalfish before and after reef settlement. PeerJ. 2016;4:e2412

114. Pfister CA, Gilbert JA, Gibbons SM. The role of macrobiota in structuring microbial communities along rocky shores. PeerJ. 2014;2:e631.

115. Sanchez E, Bletz MC, Dunsch L, Bhuju S, Geffers R, Jarek M, et al. Cutaneous bacterial communities of a poisonous salamander: a perspective from life stages, body parts and environmental conditions. Microb Ecol. 2016;73:455-65.

116. Kueneman JG, Parfrey LW, Woodhams DC, Archer HM, Knight R, McKenzie VJ. The amphibian skin-associated microbiome across species, space and life history stages. Mol Ecol. 2014;23:1238-50.
117. Sickel W, Grafe TU, Meuche I, Steffan-Dewenter I, Keller A. Bacterial diversity and community structure in two Bornean Nepenthes species with differences in nitrogen acquisition strategies. Microb Ecol. 2016;71:938-53.

118. Loudon AH, Woodhams DC, Parfrey LW, Archer HM, Knight R, McKenzie V, et al. Microbial community dynamics and effect of environmental microbial reservoirs on red-backed salamanders (Plethodon cinereus). ISME J. 2014;8: 830-40.

119. Kohl KD, Varner J, Wilkening JL, Dearing MD. Gut microbial communities of American pikas (Ochotona princeps): evidence for phylosymbiosis and adaptations to novel diets. J Anim Ecol. 2018;87:323-30.

120. Menke S, Meier M, Melzheimer J, Mfune JKE, Heinrich S, Thalwitzer S, et al. Oligotyping reveals differences between gut microbiomes of free-ranging sympatric Namibian carnivores (Acinonyx jubatus, Canis mesomelas) on a bacterial species-like level. Front Microbiol. 2014;5:526.

121. Hammer TJ, Janzen DH, Hallwachs W, Jaffe SP, Fierer N. Caterpillars lack a resident gut microbiome. Proc Natl Acad Sci U S A. 2017;114:9641-6.

122. Wang Q, Garrity GM, Tiedje JM, Cole JR. Naive Bayesian classifier for rapid assignment of rRNA sequences into the new bacterial taxonomy. Appl Environ Microbiol. 2007:73:5261-7.

123. Mcdonald D, Price MN, Goodrich J, Nawrocki E, DeSantis TZ, Probst A et al. An improved Greengenes taxonomy with explicit ranks for ecological and evolutionary analyses of bacteria and archaea. ISME J. 2012;6:610-8

124. Price MN, Dehal PS, Arkin AP. FastTree 2 - approximately maximumlikelihood trees for large alignments. PLoS One. 2010;5:e9490.

125. Fick SE, Hijmans RJ. WorldClim 2: new 1-km spatial resolution climate surfaces for global land areas. Int J Climatol. 2017;37:4302-15.

126. Sbrocco EJ, Barber PH. MARSPEC: ocean climate layers for marine spatial ecology: ecological archives E094-086. Ecology. 2013;94:979.

127. Kuhn M. Caret: classification and regression training. Astrophys Source Code Libr. 2015.

128. Hedges SB, Dudley J, Kumar S. TimeTree: a public knowledge-base of divergence times among organisms. Bioinformatics. 2006;22:2971-2.

129. Paradis $\mathrm{E}$, Schliep K. Ape 5.0: an environment for modern phylogenetics and evolutionary analyses in R. Bioinformatics. 2019;35:526-8.

130. Jombart T, Dray S. Adephylo: exploratory analyses for the phylogenetic comparative method. Bioinformatics. 2008;26:1907-1909.

131. Fox J, Weisberg S. An $\{R\}$ companion to applied regression. 2nd ed. SAGE Publications, Inc., Thousand Oaks; 2011.

132. SYSTAT. Systat Software, San Jose; 2002.

133. Oksanen J, Blanchet FG, Friendly M, Kindt R, Legendre P, McGlinn D, et al. Vegan: community ecology package. R package verion 2; 2017. p. 4-2.

134. McMurdie PJ, Holmes S. Phyloseq: an R package for reproducible interactive analysis and graphics of microbiome census data. PLoS One. 2013;8:e61217.

135. Revell LJ. Phytools: an R package for phylogenetic comparative biology (and other things). Methods Ecol Evol. 2012;3:217-23.

136. Zug R, Hammerstein P. Still a host of hosts for Wolbachia: analysis of recent data suggests that $40 \%$ of terrestrial arthropod species are infected. PLoS One. 2012;7:e38544

137. Sazama EJ, Ouellette SP, Wesner JS. Bacterial endosymbionts are common among, but not necessarily within, insect species. Environ Entomol. 2019;48: 127-33.

138. Sazama EJ, Bosch MJ, Shouldis CS, Ouellette SP, Wesner JS. Incidence of Wolbachia in aquatic insects. Ecol Evol. 2017;7:1165-9.

139. De Oliveira CD, Gonçalves D da S, Baton LA, PHF S, Carvalho FD, Moreira LA Broader prevalence of Wolbachia in insects including potential human disease vectors. Bull Entomol Res. 2015;105:305-15.

140. Weinert LA, Araujo-Jnr EV, Ahmed MZ, Welch JJ. The incidence of bacterial endosymbionts in terrestrial arthropods. Proc R Soc B. 2015;282:20150249.

141. Zug R, Hammerstein P. Bad guys turned nice? A critical assessment of Wolbachia mutualisms in arthropod hosts. Biol Rev. 2015:90:89-111.

142. Terradas G, Allen SL, Chenoweth SF, McGraw EA. Family level variation in Wolbachia-mediated dengue virus blocking in Aedes aegypti. Parasit Vectors. 2017;10:622

143. Zhang $Y$, Yang $K$, Zhu Y, Hong $X$. Symbiont-conferred reproduction and fitness benefits can favour their host occurrence. Ecol Evol. 2018;8:1626-33.

144. Carrington LB, Tran BCN, Le NTH, Luong TTH, Nguyen TT, Nguyen PT, et al. Field-and clinically derived estimates of Wolbachia-mediated blocking of dengue virus transmission potential in Aedes aegypti mosquitoes. Proc Natl Acad Sci U S A. 2018;115:361-6. 
145. O'Neill SL, Ryan PA, Turley AP, Wilson G, Retzki K, Iturbe-Ormaetxe I, et al. Scaled deployment of Wolbachia to protect the community from dengue and other Aedes transmitted arboviruses. Gates Open Res. 2018;2:36.

146. Hughes GL, Vega-Rodriguez J, Xue P, Rasgon JL. Wolbachia strain wAlbB enhances infection by the rodent malaria parasite Plasmodium berghei in Anopheles gambiae mosquitoes. Appl Environ Microbiol. 2012;78:1491-5.

147. Rancès $E$, Yixin HY, Woolfit M, McGraw EA, O'Neill SL. The relative importance of innate immune priming in Wolbachia-mediated dengue interference. PLoS Pathog. 2012;8:e1002548.

148. Bian G, Joshi D, Dong Y, Lu P, Zhou G, Pan X, et al. Wolbachia invades Anopheles stephensi populations and induces refractoriness to Plasmodium infection. Science. 2013;340:748-51.

149. Zélé F, Nicot A, Berthomieu A, Weill M, Duron O, Rivero A. Wolbachia increases susceptibility to Plasmodium infection in a natural system. Proc $R$ Soc B. 2014:281:20132837.

150. Dodson BL, Andrews ES, Turell MJ, Rasgon JL. Wolbachia effects on Rift Valley fever virus infection in Culex tarsalis mosquitoes. PLoS Negl Trop Dis. 2017;11:e0006050

151. Diouf M, Miambi E, Mora P, Frechault S, Robert A, Rouland-Lefèvre C, et al. Variations in the relative abundance of Wolbachia in the gut of Nasutitermes arborum across life stages and castes. FEMS Microbiol Lett. 2018;365:46.

152. Walker T, Johnson PH, Moreira LA, Iturbe-Ormaetxe I, Frentiu FD, McMeniman CJ, et al. The wMel Wolbachia strain blocks dengue and invades caged Aedes aegypti populations. Nature. 2011:476:450.

153. Moreira LA, Iturbe-Ormaetxe I, Jeffery JA, Lu G, Pyke AT, Hedges LM, et al. A Wolbachia symbiont in Aedes aegypti limits infection with dengue, Chikungunya, and Plasmodium. Cell. 2009;139:1268-78.

154. Hurst GDD, Johnson AP, JHG v S, Fuyama Y. Male-killing Wolbachia in Drosophila: a temperature-sensitive trait with a threshold bacterial density. Genetics. 2000;156:699-709.

155. Reynolds KT, Thomson LJ, Hoffmann AA. The effects of host age, host nuclear background and temperature on phenotypic effects of the virulent Wolbachia strain popcorn in Drosophila melanogaster. Genetics. 2003;164:1027-34

156. Arnold PA, Levin SC, Stevanovic AL, Johnson KN. Drosophila melanogaster infected with Wolbachia strain wMelCS prefer cooler temperatures. Ecol Entomol. 2019:44:287-90

157. Pascar J, Chandler CH. A bioinformatics approach to identifying Wolbachia infections in arthropods. PeerJ. 2018;6:e5486.

158. Jeffries CL, Tantely LM, Raharimalala FN, Hurn E, Boyer S, Walker T. Diverse novel resident Wolbachia strains in Culicine mosquitoes from Madagascar. Sci Rep. 2018;8:17456.

\section{Publisher's Note}

Springer Nature remains neutral with regard to jurisdictional claims in published maps and institutional affiliations.

Ready to submit your research? Choose BMC and benefit from:

- fast, convenient online submission

- thorough peer review by experienced researchers in your field

- rapid publication on acceptance

- support for research data, including large and complex data types

- gold Open Access which fosters wider collaboration and increased citations

- maximum visibility for your research: over $100 \mathrm{M}$ website views per year

At $\mathrm{BMC}$, research is always in progress.

Learn more biomedcentral.com/submissions 